\title{
Managing construction site communication using the responsibility assignment matrix (RAM) system
}

\author{
Raid Shrahily ${ }^{\mathrm{a}}$, Benachir Medjdoub ${ }^{\mathrm{b}}$, Hynda Klalib $^{\mathrm{c}}$, Moulay Chalal ${ }^{\mathrm{b}}$ and Mamdooh Alwetaishi ${ }^{\mathrm{d}}$ \\ ${ }^{a}$ Architecture Department, College of Engineering, Albaha University, Alaqiq, Saudi Arabia; bschool of Architecture Design and The \\ Built Environment, Nottingham Trent University, Nottingham, United Kingdom; ' Department of Civil Engineering, Nottingham \\ Trent University, Nottingham, United Kingdom; d Department of Civil Engineering, College of Engineering, Taif University, Taif, \\ Saudi Arabia
}

\begin{abstract}
The construction industry in the UK wastes $\mathrm{f} 1$ billion per year due to construction defects that are mainly caused by a communication failure between organisations operating on the construction site. Meanwhile, the introduction of the BIM strategy has become a mandatory requirement by the government in order to reduce costs by $33 \%$ and speed up project del ivery by $50 \%$ without sacrificing quality. Since then, the industry has seen a global reaction to the BIM Level 2 programme and a significant cost-saving in the UK of $£ 1.2$ billion in $2014 / 15$, rising from $£ 840$ million in $2013 / 14$. However, communication remains a major issue to achieve the BIM Level 3 as it requires all organisations involved to use a single platform to facili-tate communication. This paper, therefore, fits within the BIM implementation programme by addressing the communication issues and construction defects on-site toward formulating a communication frame-work for the construction industry in the UK. This will help optimise communication and manage con- struction defects efficiently. The study takes advantage of the Responsibility Assignment Matrix (RAM), the widely known management system and uses it to assign communication tools for each organisation in relation to the construction stages throughout two phases of data collection. Phase 1 involves two qualitative data collection methods of an in-depth review of the relevant literature (document analysis) and construction site observation. To facilitate site observation and data collection, the researcher colla- borated with GF Tomlinson group, a Derby-based construction company, as the case study. Phase 2 involves an online survey, targeting a total number of 328 participants, including professionals and aca- demics. Results of phase 1 are presented as the Communication Tools Assignment 1 (CTA1) and phase 2 results inform the Communication Tools Assignment 2 (CTA2). The study contribution is to develop a framework that recommends the appropriate communication tools for organisations at different construc- tion stages, and which shows the possible types and causes of construction defects. Moreover, the study found three types of construction defects by applying 3D laser scanning for framework mentoring.
\end{abstract}

\section{KEYWORDS}

Responsibility assignment matrix; standard work breakdown structure; standard organisation breakdown structure; communication tools assignment; construction defects; BIM

\section{Introduction}

The construction defects generate unnecessary work and effort to redo the construction activities that are incorrect in the first place (Park et al. 2013). Defects are mainly caused by communi- cation failures between stakeholders operating on construction sites (Wang 2007). The BRE (Building Research Establishment) stated that, every year, over $£ 1$ billion is spent on construction defects to repair or rebuild (Stupart 2003; Goh et al. 2014). This is due to a reliance on $2 \mathrm{D}$ drawings which is ineffective as the construction works are mostly planned by sketching over the $2 \mathrm{D}$ drawings. Some stated that such drawings are ineffective and prone to error as only experienced and well-trained organisations are able to generate a construction plan using 2D drawings (Wang 2007). Furthermore, the construction process involves several different organisations and stakeholders who have to work together in many activities that need to be organised. Mainly, the 2D drawings and the associated documents are the most commonly used means to communicate and share informa- tion between parties (Goh et al. 2014). This information contains data of the architectural components and details, the engineering systems of the structure, mechanical services, and other data that raise the level of complexity even higher (Steel et al. 2012). To safeguard the on-site productivity and improve communication, companies attempt to find solutions to the 2D problems using technologies such as the Lima Document and Project Management tool. This cloud-based software delivers data, draw-ings, documents and design management solutions to architec- ture, engineering and other construction firms involved in the project. Even though these tools help companies organise and manage complex data, models and designs are still exchanged frequently using 2D drawings, mainly for communicating with external stakeholders (Emmitt and Gorse 2011; Alreshidi et al. 2016b). Discussing the collaboration within the group itself between two designers from the same team, for example is more complex and group team members need to collaborate to com- plete the construction tasks (Alreshidi et al. $2016 \mathrm{~b}$ ). Moreover, the use of both 3D and 2D drawings to share knowledge can lead to more miscommunication issues and defects unless mul- tiple data inspections are performed, which is not costeffective (Steel et al. 2012). An example of such miscommunication is that the design specifies triple glazing windows but contractors and workers install double glazing ones instead because communicat- ing with 2D drawings is not sufficiently clear. Such 
miscommunication will result in additional costs in the long run. Similarly, using just the 3D drawing for communication will not help. In general, communication-based 2D and 3D drawings are not efficient since the communication practices used to assign on-site responsibilities are not fully comprehensive and not free from error (Emmitt and Gorse 2011). Even if, with all the required 2D and 3D drawings, the specifications and the sup- porting documents are completed and submitted according to the contract agreement, communication is not free from error as design details are constantly updating (Emmitt and Gorse 2011). A possible reason for this issue is the reliance on $2 \mathrm{D}$ and $3 \mathrm{D}$ drawings which are the key elements in communicating and translating engineering principles and design calculations into a physical construction (Goh et al. 2014). These communication errors can generate additional costs from material use and wrong specifications. Similarly, implementing changes at the construc- tion stage without the associated updates can account for numer- ous defects.

The above discussion has highlighted the importance of exchanging and visualising the construction information as, otherwise, it can lead to miscommunication between stakehold- ers. In response to these challenges, the UK government initiated a BIM implementation plan consisting of four levels, with Level 2 being fully implemented in early 2016 as a compulsory proced- ure in public sector projects (MacLeamy 2016). Building Information Modelling or BIM is a method of building a net- work system to manage the essential data of any project in digital format throughout the project lifecycle (Howard and Penttila 2006). With the BIM implementation plan, the govern- ment collaborates with the industry to achieve the benefit of cost reduction in the construction industry. In fact, literature reports that, by 2015, BIM had contributed to substantial construction cost-savings of between $15 \%$ and $20 \%$ of the capital project according to The Industrial strategy: government and industry in partnership (MacLeamy 2016). In addition, some studies com- pared projects that implemented BIM to others that did not, found that BIM did save time and cost (Ahankoob et al. 2019). Even though BIM has these advantages, though, not all the architecture, engineering and construction (AEC) firms are expe- riencing the full potential of BIM yet. That is because of a num- ber of issues such as the required level of skills and experience to deal with BIM and implement it, which are both highly important (Ahankoob et al. 2019; Alwisy et al. 2019). More recently, the government moving to BIM Level 3 and set out an approach known as "Digital Built Britain" (DBB) (Cabinet Office 2011). Although BIM is meant to facilitate collaboration between the stakeholders at different stages throughout the entire project lifecycle (Alreshidi et al. 2016a), the tool is mostly used for communication at the design stage only and not for the construction stages (Cabinet Office 2011).

To understand the on-site communication needs and chal- lenges facing different stakeholders, a qualitative and quantitative (mixed methods) approach to a set of principles is employed to guide this study through two phases of implementation. For both phases, we adopt a well-known management system, the RAM as a research method since it can provide in-depth data for the overall communication scenario. In the first phase, we performed a qualitative content analysis to define the main ele- ments of the onsite communication as well as some of the rele- vant communication tools for different groups. We started by identifying the project's tasks and stages in addition to their inter-relationships by using the Work Breakdown Structure (WBS) and Organisation Breakdown Structure (OBS).
The management system of RAM or the Accountability RACI Chart is defined as a construction management technique used to identify the construction tasks and assign responsibilities to each stakeholder. The advantage of the RAM process is that it clarifies who will perform each task and shows the possible stakeholders who might need to communicate about different activities (Yang and Chen 2009). It uses a matrix table, which makes it a stable project management representation with less chance of frequent changes in the future (Rev 2003). However, the main issue with the existing RAM is the lack of communica- tion guidelines and causes of construction defects. Instead, pro- ject managers use their experience to select the appropriate communication tools and to identify possible defects to ensure that the technical details, drawings and construction tasks are communicated effectively (Oh et al. 2015a). This is because, to date, the communication tool selection has never been addressed in any RAM system. Thus, in phase 1 , the actual research assigns appropriate communication tools, based on a comprehensive data analysis drawn from the literature review and on-site obser- vation. Phase 1 results are designated as the Communication Tool Assignment 1 (CTA1) matrix. In phase 2 of the study, a survey questionnaire designated as Communication Tool Assignment 2 (CAT2) is sent to professionals and academics to complement phase 1 findings.

A fundamental aspect of reducing construction costs is to understand the construction site communication. Therefore, this research aims to merge the actual RAM with relevant communication tools and possible defects to inform and design an effect- ive communication framework for construction sites. The framework's main feature is to combine the recommended com- munication tools for each organisation and show the construc- tion defects. To implement this concept, the study takes advantage of the RAM and follows a similar method with the exception of not only assigning work responsibilities as the trad- itional RAM did but also assigning the appropriate communica- tion tools that should be used by each organisation throughout the two phases. Phase 1 uses data from the literature review (document analysis) as well as site observation through collabor- ation with G.F. Tomlinson group. Phase 2 on the other hand uses data generated from an online survey questionnaire.

This research contributes to the already existing RAM system by adding an additional two layers of information. In addition to the existing construction work assignment that the conventional RAM has, our new framework suggests a list of communication tools that organisations should use (maximum of two to three types of tool). The second layer informs organisations of the common construc- tion defects found at each construction phase, which will help to minimise defects and reduce costs in the long run.

\section{Background}

A large proportion of construction companies are still facing challenges related to communication. With the BIM strategy implementation plan, it was expected that BIM Level 2 would improve the overall communication from the design stage to the construc- tion site. However, with the integration of multiple software tools to create BIM files, a variety of issues are emerging such as data loss, poor work efficiency and communication difficulties (Oh et al. $2015 \mathrm{~b})$. With this in mind, the industry is going to face chal- lenges in order to keep pace with the UK government's BIM implementation strategies. Increasing BIM Level 2 maturity across the industry will enable the companies to move gradually to BIM Level 3 (Bridges 2016) and to shift to an integrated and 


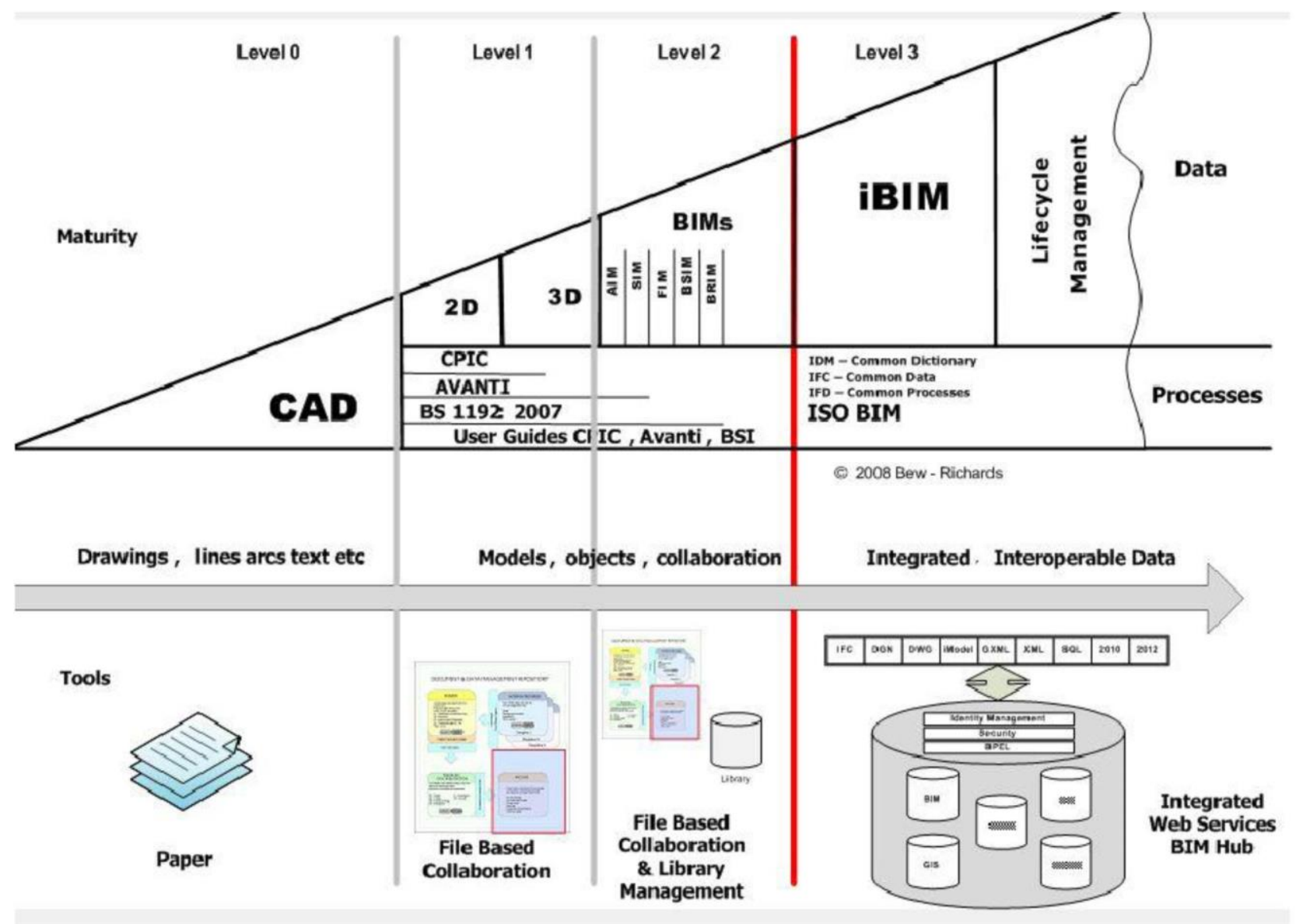

Figure 1. BIM implementation strategy (BSI 2014).

collaborative process (Figure 1). Therefore, the communication between different stakeholders needs further improvement to facilitate BIM implementation. As a result, all contributors to a project can access and modify the same model and facilitate communication between stakeholders which efficiently supports the process of information conflict analysis (Bridges 2016).

Collaboration on the construction site requires effective communication, and BIM is seen as a shared language that can mediate and improve communication. That is because - according to the Standards of Building Information Modelling - BIM is a digital representation of the physical building objects (Alwisy et al. 2019) used to improve communication. However, this is not the case because BIM implementation poses challenges relating to how the data are optimised according to stakeholders' needs to facilitate communication on the construction site (Hollermann et al. 2012). To successfully implement BIM for construction site use, it is important to study communication at the human level which presents as non-verbal, oral and written communication types. Both oral and written communication types are affected by two factors (BSI 2014; Bridges 2016). The first factor is related to the formal and informal communication tools used in the construction process (Rev 2003; Steel et al. 2012). Formal communication is represented in the form of $2 \mathrm{D}$ drawings and textual data, whereas informal communication is supported by other digital systems and technolo- gies, such as 3D virtual models and 3D laser scans (Tjell and Bosch-Sijtsema 2015). The second factor relates to human inter-action, which plays a major role in the process and requires good relationships between the team members. This communication information can include structural details, material specifications, building services details, mechanical/electrical installation information, structural elements' dimensions and objects' sizes, among others. Failure to maintain these relationships may demotiv- ate stakeholders from improving their communication (Tjell and BoschSijtsema 2015). Furthermore, it could lead to recriminations and conflicts between the organisations' members, which would cause a loss of trust and communication restrictions resulting in even more construction defects and additional costs (Hollermann et al. 2012; Oh et al. 2015b). For these reasons, it is important to undertake a clear communication chain study that addresses the practices and weaknesses in order to assign communication respon- sibilities to the involved organisation's teams. Two research studies from 2010 and 2012 tried to improve communication by support- ing the companies' leadership with BIM based on the selection of organisations, their role on-site, and the relation each organisation has with the owner ( $\mathrm{Gu}$ and London 2010; Khosrowshahi and Arayici 2012). Similarly, another researcher suggested that the proj- ect's owner is the key contributor for who the communication needs to be improved (Goh et al. 2014). However, these studies have some drawbacks as they create two different groups and the communication between the owner and other organisations has not been investigated. The first group, leaders who already have good communication skills, is supported with an additional BIM tool whereas the second group, such as workers, lacks assistance. As a result, an integrated approach is essential to point out the issues of communication and construction defects. Some researchers believe that the communication through architectural plans is necessary to collaborate with other disciplines since architects are the only organisation with this type of skill. Once again, this study ignored other organisations, which might be better supported by BIM (BSI 2014; Tjell and Bosch-Sijtsema 2015). 


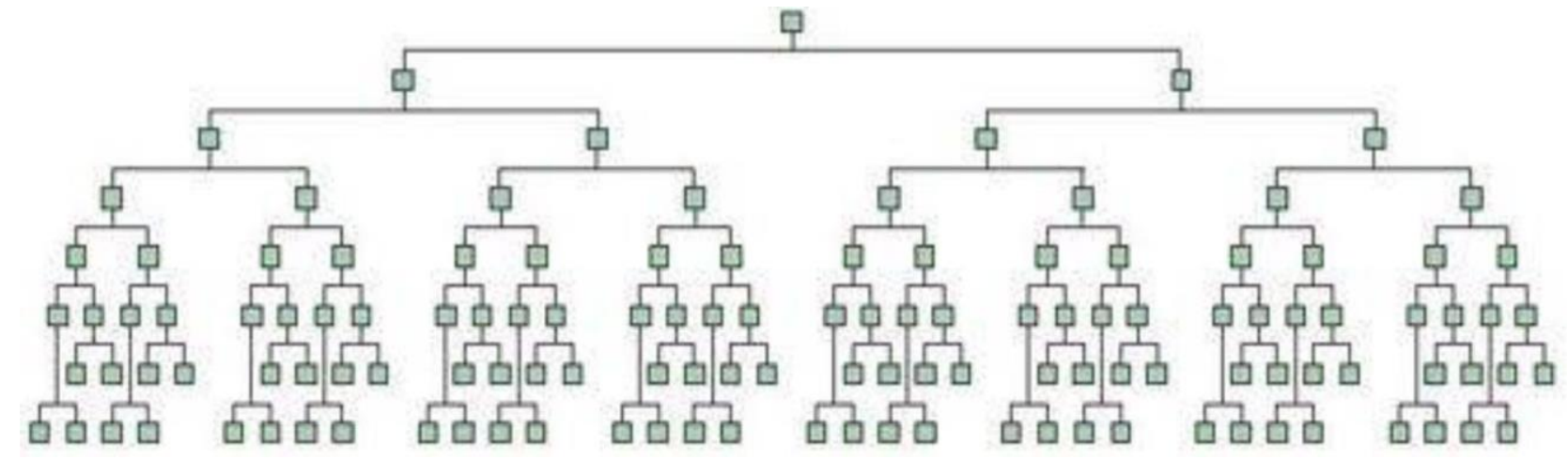

Figure 2. The hierarchical or vertical organisation structure.

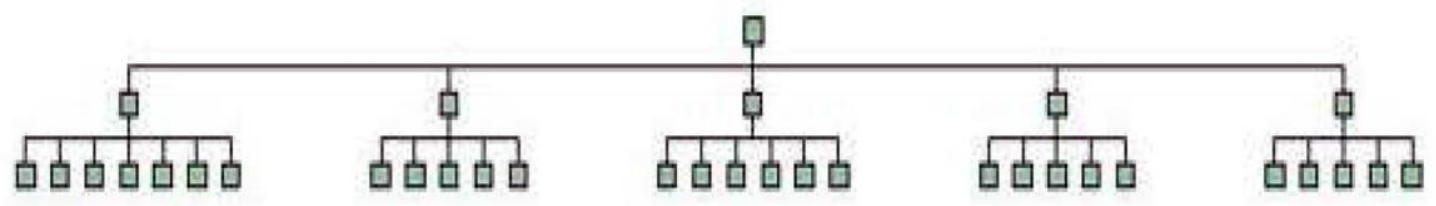

Figure 3. The horizontal or flat organisation structure.
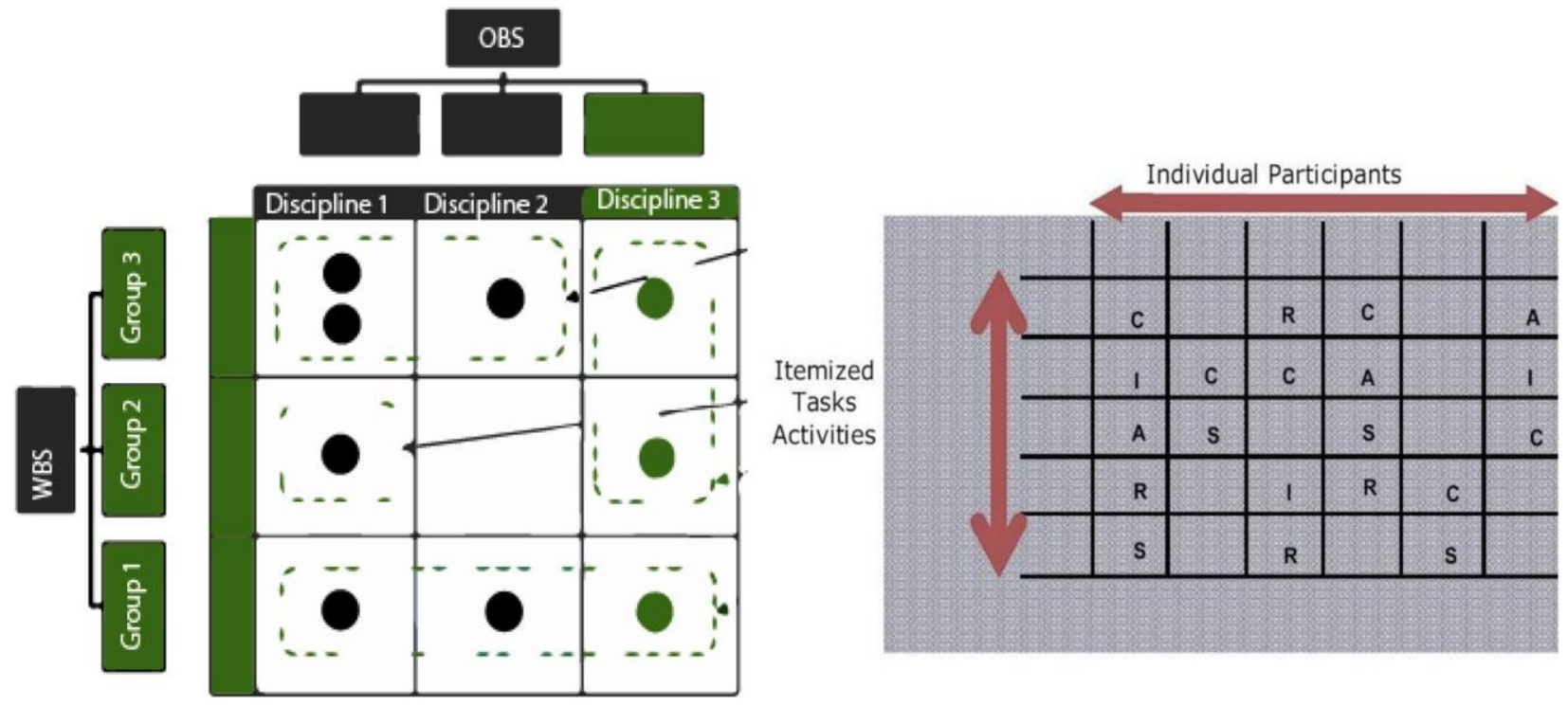

Figure 4. Examples of the Responsibility Assignment Matrix (Wu and Fan 2008).

The previous disruptions highlight the connection between BIM and RAM as both are about communication improvement (Oh et al. 2015b). Unlike the research methods employed by previous studies, we undertake a more comprehensive communication study approach, taking into account the RAM principle of engaging all stakeholders onsite, starting from the project owner and including others such as architects, contractors, suppliers, and workers, among others. Therefore, this research defines stakeholders as those operat- ing on construction sites only, who can detect construction defects more accurately and effectively if their communication is supported with BIM. In addition, none of the previous studies focused on the construction stages to understand where the miscommunications occurred, which one of the stakeholders' personnel could prevent it, and how they could achieve this. Another objective is to adapt the existing RAM by assigning the appropriate communication tool to the on-site personnel. This paper addresses the following research questions: a. What are the most effective communication tools used on construction sites?

b. Which team members are the most active on-site in terms of communication?

c. Which construction stages are more exposed to construction defects and what are the causes?

Construction defects are considered one of the most common causes of increased costs in the industry, and only limited research has explored this aspect (Atkinson 1999). For example, it was stated that construction defect represent $4 \%$ of the contract value in resi- dential projects (Mills et al. 2009). Others found that the construc- tion defects costs are $3.15 \%$ and $2.40 \%$ for residential and industrial buildings, respectively (Love and Li 2000). Therefore, highlighting the causes of defects is an essential step toward the cost reduction objective supported by the BIM implementation plan (Cabinet Office 2011). In order to avoid construction defects as much as pos- sible, it becomes more urgent to identify the causes. Some 

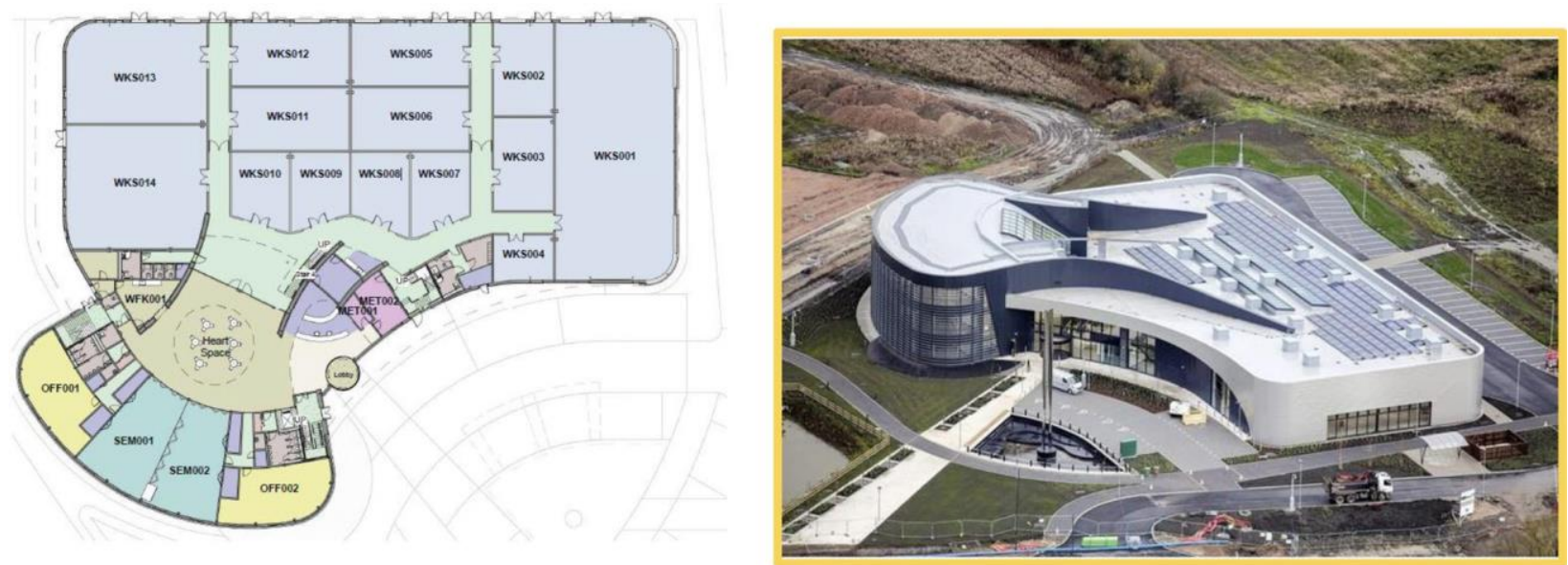

Figure 5. iHub centre for the case study.

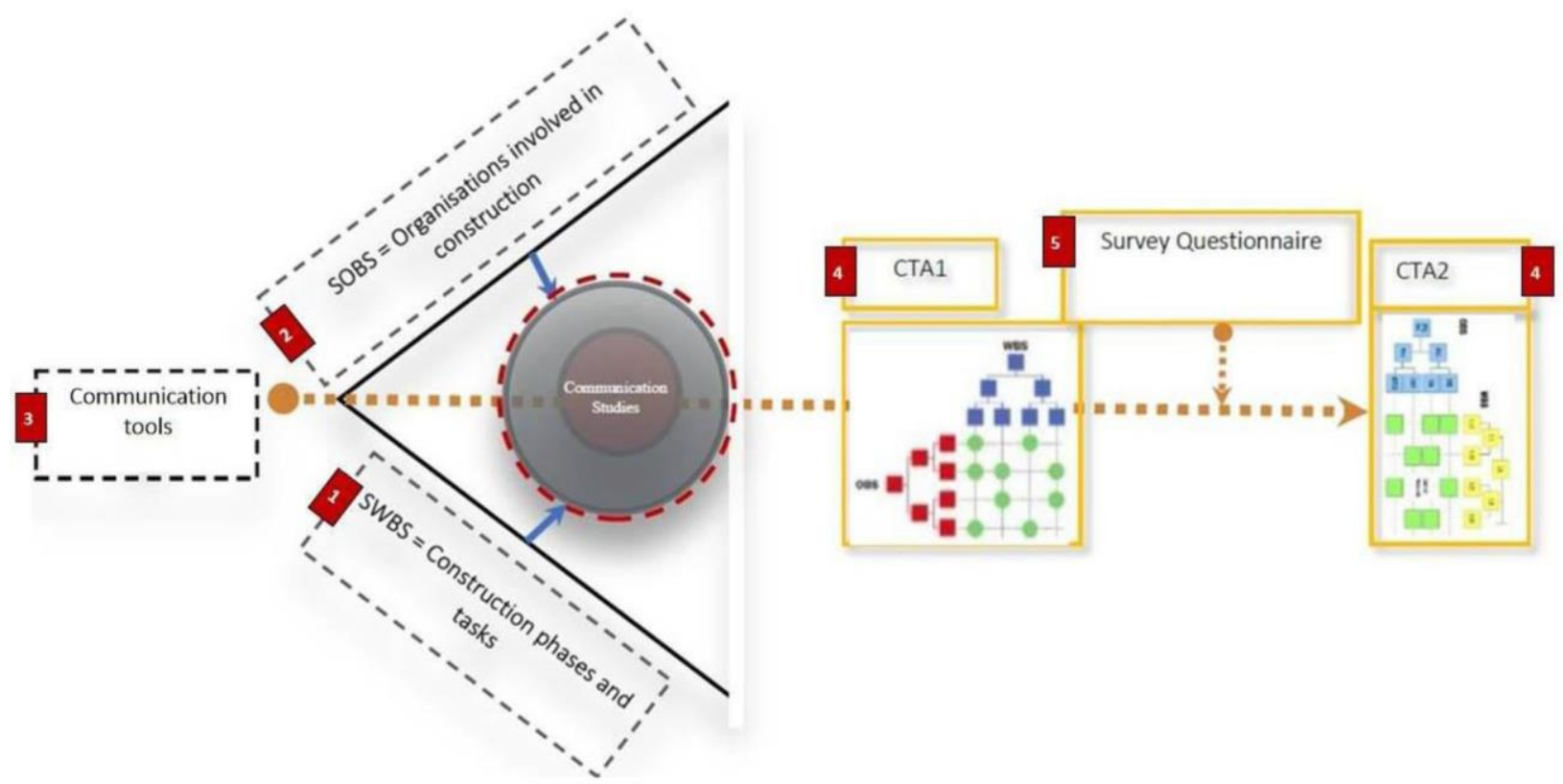

Figure 6. Research methodology diagram.

researchers tend to associate the defects with documentation errors (Srivastav 2010). Others stated that defects present at the design stage are caused by the weak management system found in the architecture firms (Rounce 1998).

Research found that $50 \%$ of the construction defects costs are caused by lack of motivation; more than $25 \%$ of the defects costs is caused by lack of knowledge, and $12.5 \%$ of the overall defects cost is caused by misinterpretation (Josephson and Hammarlund 1999). In addition, this statement confirms that miscommunica- tion and misinterpretation are the sources of human errors that cause defects. In addition, construction defects are mostly detected by the owner, and only after the project delivery, which makes it more difficult to define the cause when the owner reports it (Shirkavand et al. 2016).

\section{The vertical and horizontal organisation system}

Vertical and horizontal structural systems have a significant effect on the communication flow. For example, in a vertical sys- tem, there are two types of lack of communication between the project owner and suppliers. First, the vertical system suggests that there is no communication between them at any stage of the construction process - see an example of the vertical system in Figure 2. Second, the support the owner should get from the suppliers is often lacking. Similarly, in a horizontal system, there is a lack of communication between members of the same team - see Figure 3. These issues are noticed within the design team, for example, and with some of the on-site stakeholders such as the workers (Atkinson 1999).

\section{The management system of the responsibility assignment matrix (RAM)}

RAM is a management system, based on a matrix chart used to manage human resource (HR) planning (Figure 4). It is widely used to create a connection between construction tasks and team members (Yang and Chen 2009). Using a similar system of cross- function collaboration may avoid construction complexity and help to solve issues on-site. Literature mentioned that RAM is the most used management system as it designates the roles and responsibil- ities of the project members (Melnic and Puiu, 2011). However, in order to complete the matrix table, the WBS and OBS are required. 


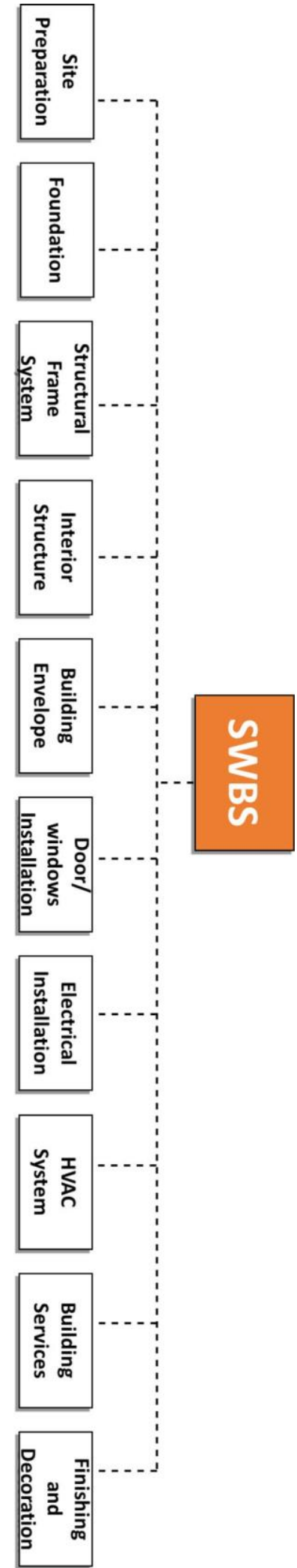

Figure 7. Construction work breakdown structure. Change WBS to SWBS

The WBS is a project's work classification, divided into sub-working tasks to achieve the final project (Dainty and Moore 2006). On the other hand, OBS is a hierarchical structure that shows, in a graph- ical representation, the relationships between organisations where managers are at the top of the structure, and individual

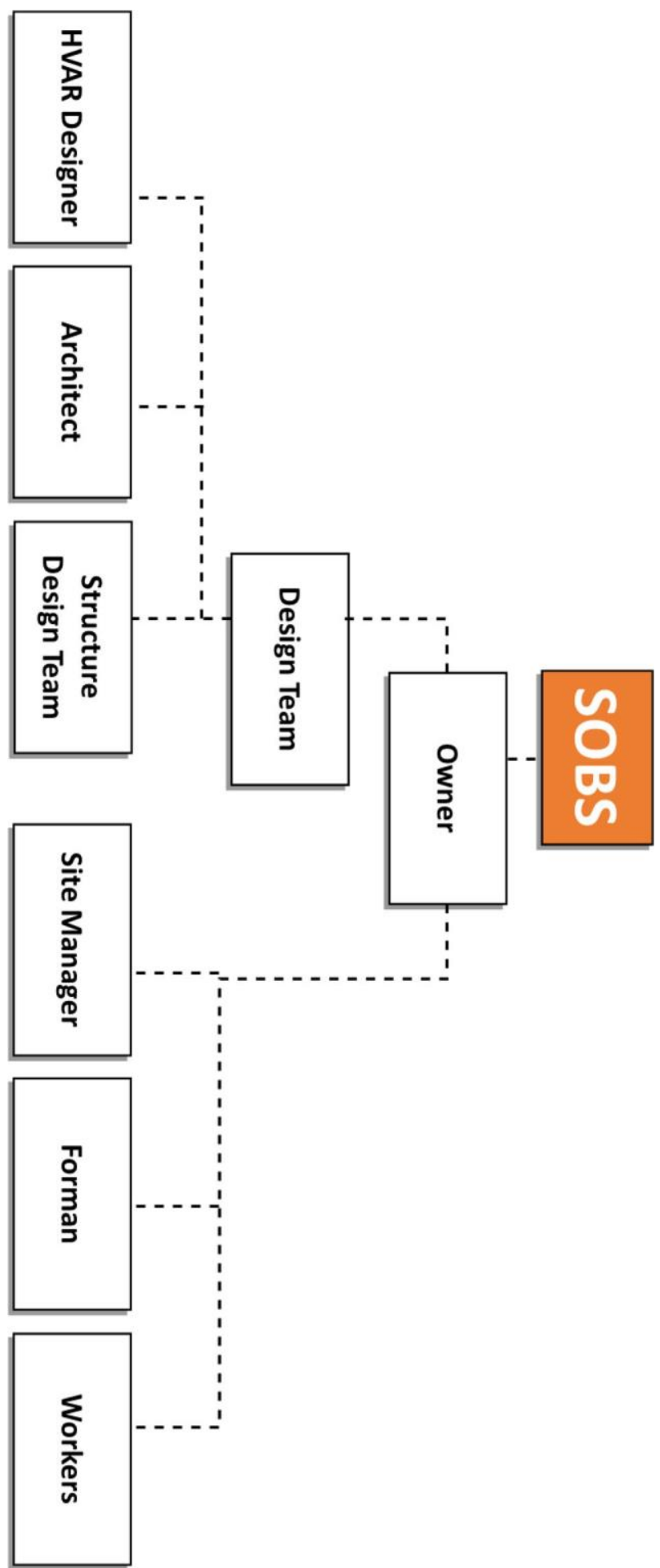

Figure 8 . The construction organisation breakdown structure.

organisations are at the bottom of the structure (Dainty and Moore 2006; Melnic and Puiu, 2011).

\section{Types of communication tools and types of data}

There are verbal and nonverbal forms of communication such as texts, emails and faxes as well as telephone calls and, meetings; all are examples of common communication tools. Each tool has its specific advantages and disadvantages in relation to how the data are communicated. 2D and 3D drawings are used to 


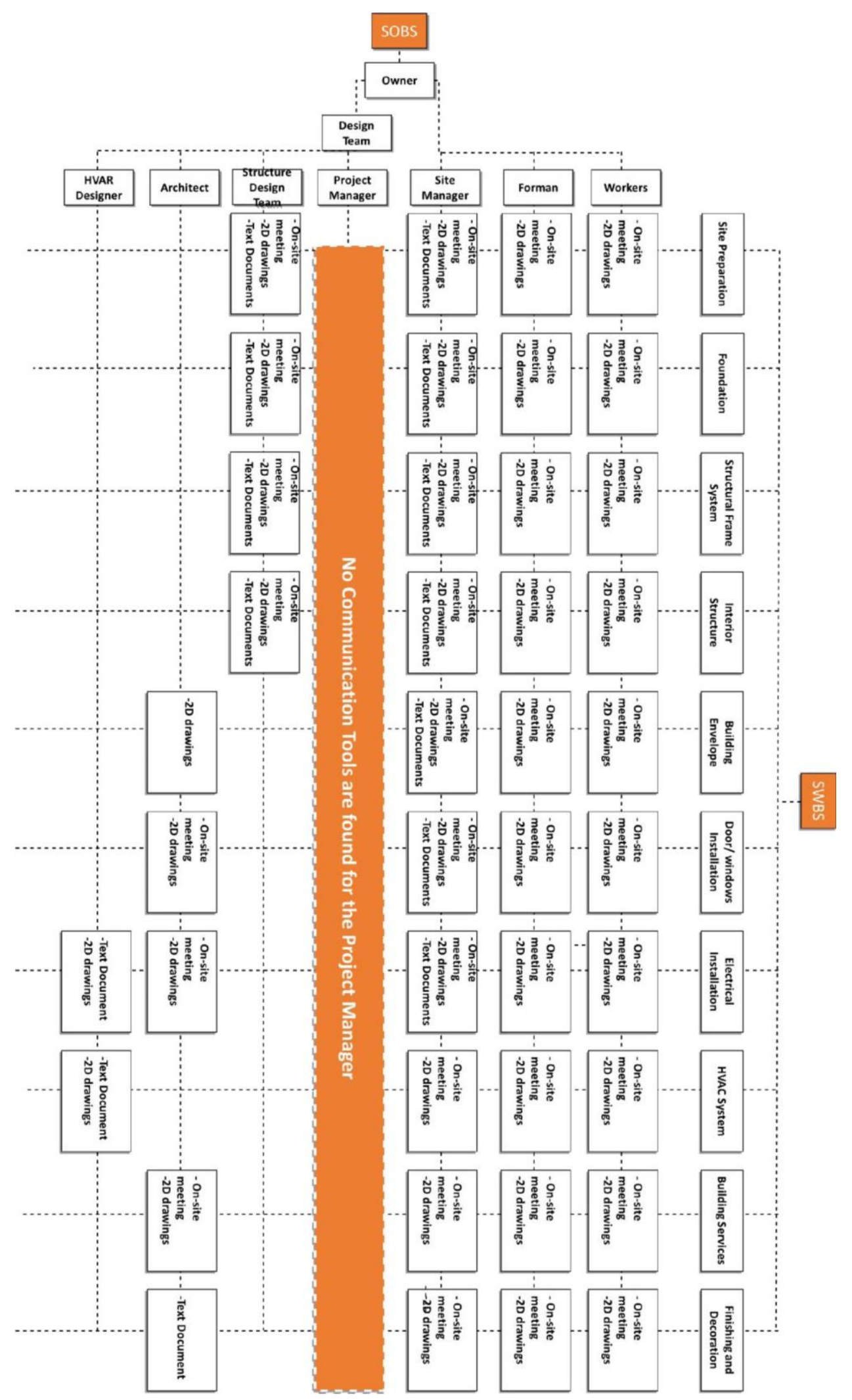

Figure 9. Communication framework of phase 1, CTA1.

describe the three-dimensional objects; their exact location in space, real size and shape all are based on the work experience (Rossi 2012). On-site meetings, on the other hand, are held to discuss a specific issue and to follow up the construction pro- gress (Dainty and Moore 2006). Documentary and email tools are both used to communicate the design details, the supervision process, and how the construction tasks are performed (Yu and Hsu 2013). The phone call tool is used to share tactical informa- tion related to coordinating activities and for propriety informa- tion (Modi and Mabert 2007). Finally, the direct instruction or 


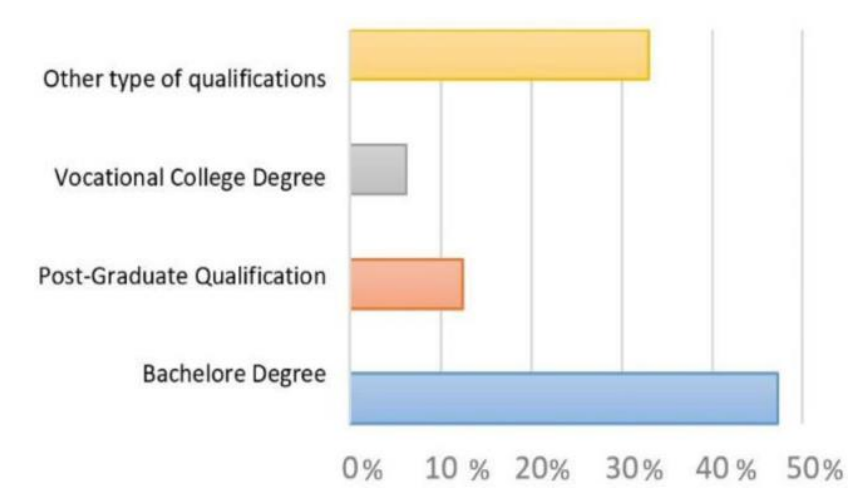

Figure 10. Participants' qualification percentages.

verbal order is used to pass on technical details when communicating with employees to make sure they receive the message correctly (Senaratne and Ruwanpura 2015).

In some cases, communicating via emails or conducting an on-site meeting is sufficient. However, Dainty and Moore (2006) recommended the use of additional communication tools such as a phone call or a face-to-face meeting when emails cannot clarify the required work (Dainty and Moore 2006). This is because establishing a clear chain of communication usually starts with the selection of the appropriate tools. For instance, communica- tion between owners and contractors mainly occurs through architects who can communicate via a variety of tools (drawings, meetings, phone calls, etc.). For the above-stated reasons, it is crucial to establish a comprehensive study where all communica- tion tools attract fair consideration when identifying the more effective ones (Dainty and Moore 2006).

The proposed framework provides an adequate understanding of on-site communication. It enriches the RAM matrix with the recommended communication tools and identifies the common causes of defects.

\section{Methodology}

The study was conducted in collaboration with the G. F. Tomlinson group who provided us with a case study of the Derby Innovation Centre building or iHub. This is a research centre with workshops, studios and office spaces based in Derby's marketplace for the technology innovation sector; see Figure 5. The following steps describe how this collaboration was entered into in order to develop the communication framework.

Step 1 is the WBS used to create the individual construction stages. In Step 2, the project's personnel grouping is established through the OBS to identify the only working groups and stake- holders operating on the construction site. Step 3 defines the types of communication tools involved. In Step 4 each communication tool is assigned to the associated groups and the construction stage. Step 5 validates the resulted communication framework. The pro- cess of those five steps forms the RAM system (Golany and Shtub 2001), as shown in Figure 6. The WBS, the OBS and the relevant communication tools are adapted for construction projects in the UK only. These four steps are used for the two phases (CAT1 and CAT2) of the present study whereas the validation step will be only for the CTA2. Furthermore, the framework helps to identify defects' causes at each construction stage to alert stakeholders and work towards a "zero defects policy".

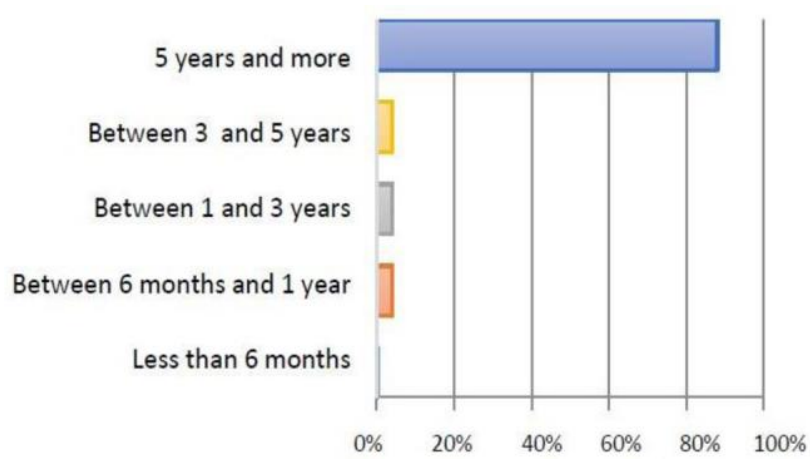

Figure 11. Participants' years of work experience.

\section{Step 1: WBS}

Due to the complexity of the construction process and its various stages, the WBS can be designed in a range of forms (Mulenburg 2010). Therefore, it is unrealistic to implement a single WBS for all types of construction projects in the UK. For the stated reasons, we opted for a Standard Work Breakdown Structure (SWBS) by only incorporating the common construction tasks and stages (Chudley and Greeno 2008) of all construction projects.

\section{Step 2: $O B S$}

After developing the SWBS, it is necessary to build a universal organisation breakdown structure which takes into account different types of projects. Traditionally, most OBS is built on a hierarchical structure that can hide some information which can affect the communication efficiency (Leen and Garca 2011). The organisations' selection had to fit a wide range of construction projects in the UK and is termed the Standard Organisation Breakdown Structure (SOBS). Thus, the personnel grouping has been assigned based on the common tasks and stages (Chudley and Greeno 2008) found in the SWBS. We selected organisations from the literature based on their frequent presence in construc- tion projects.

\section{Step 3: Communication tools}

The study aims to assign communication tools to each organisa- tion. Once again, using all types of tool seems to be unreliable. Instead, three types of communication tool are adopted for phase 1, including 2D drawings, on-site meetings, and text-based documents (Shrahily et al. 2015). As for phase 2, the study imple- ments additional tools of direct instructions and phone calls, based on experts' recommendations (Shrahily et al. 2016).

\section{Step 4: RAM and construction defects framework}

The study uses the RAM matrix cross-function structure that includes the listed WBS, OBS (Chudley and Greeno 2008) and communication tools. The framework is to assign the communication tools to organisations in relation to the construction stages, resulting in CTA1 and CTA2. In addition, the communi- cation CTA2 includes the common causes of construction defects that stakeholders need to be aware of when communicating on-site. 


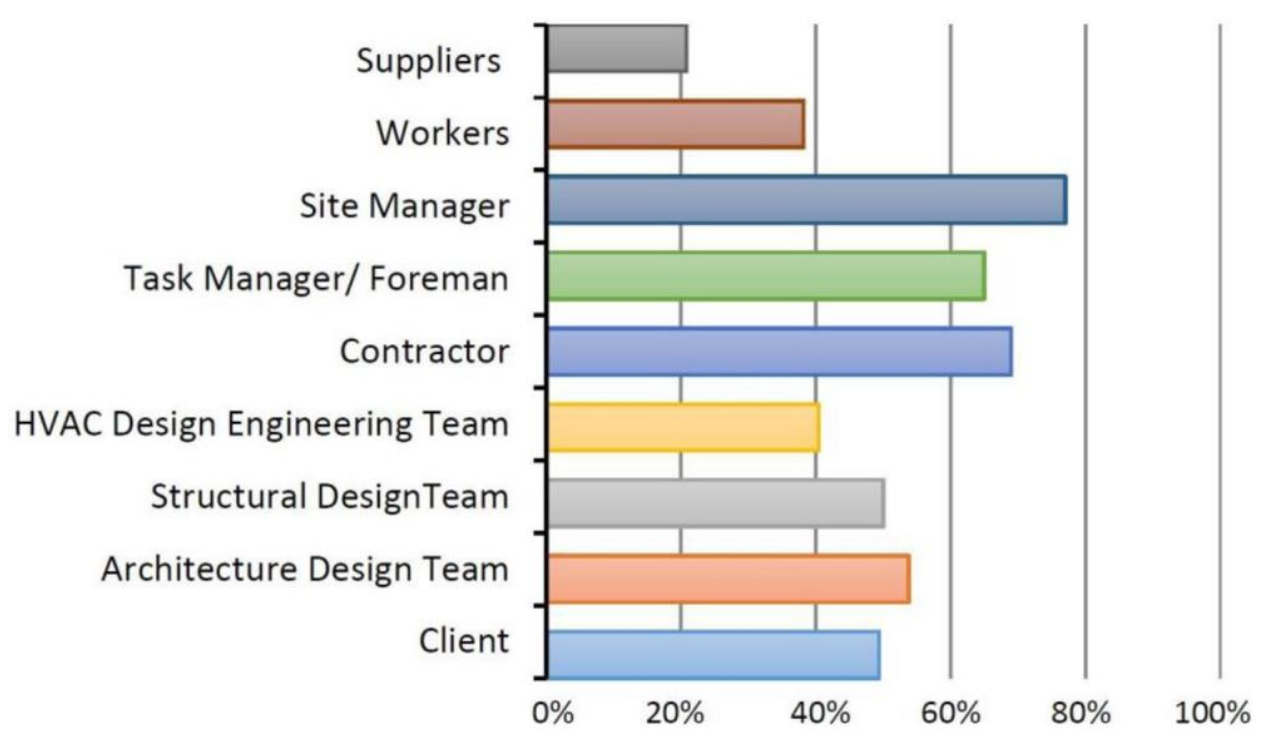

Figure 12. The time spent on the construction site by the organisation.

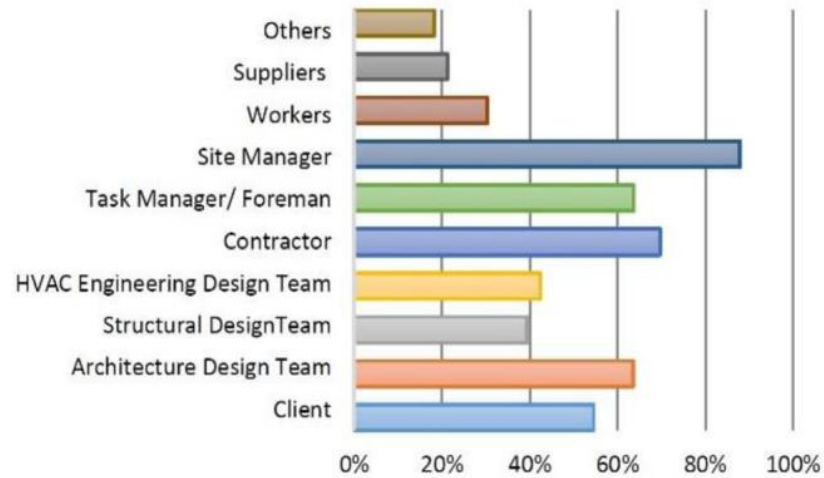

Figure 13. Responsibility for detecting defects on a construction site.

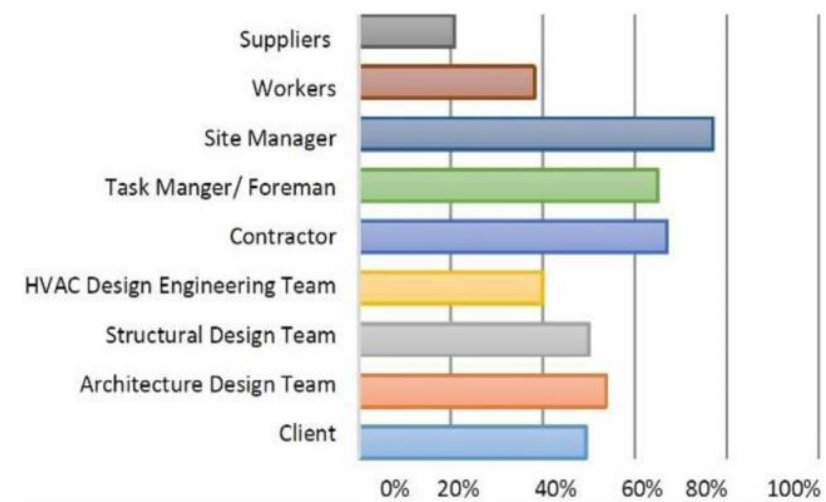

Figure 14. Organisations ability to detect construction defects.

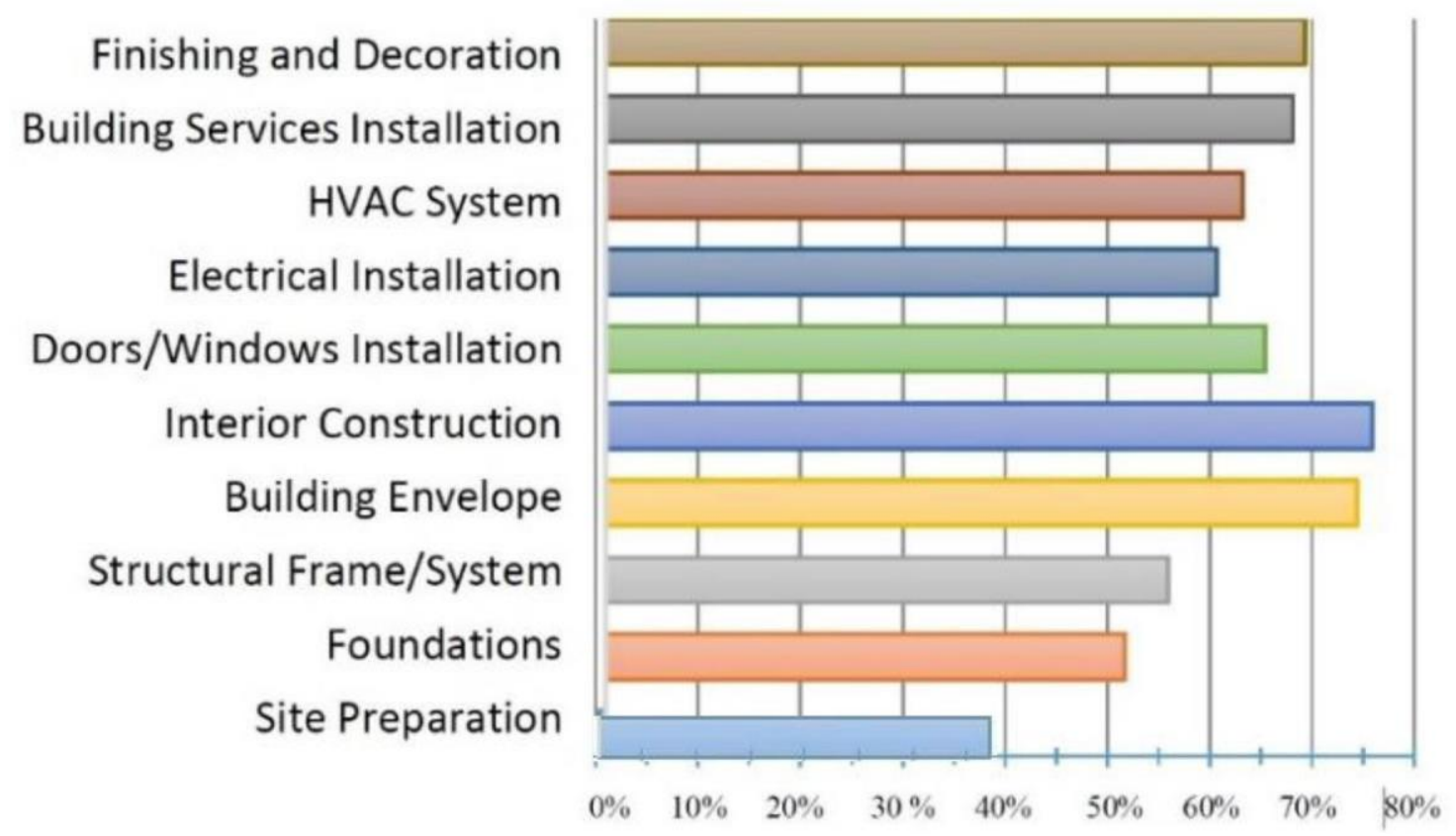

Figure 15. Construction stages that are most exposed to construction defects. 


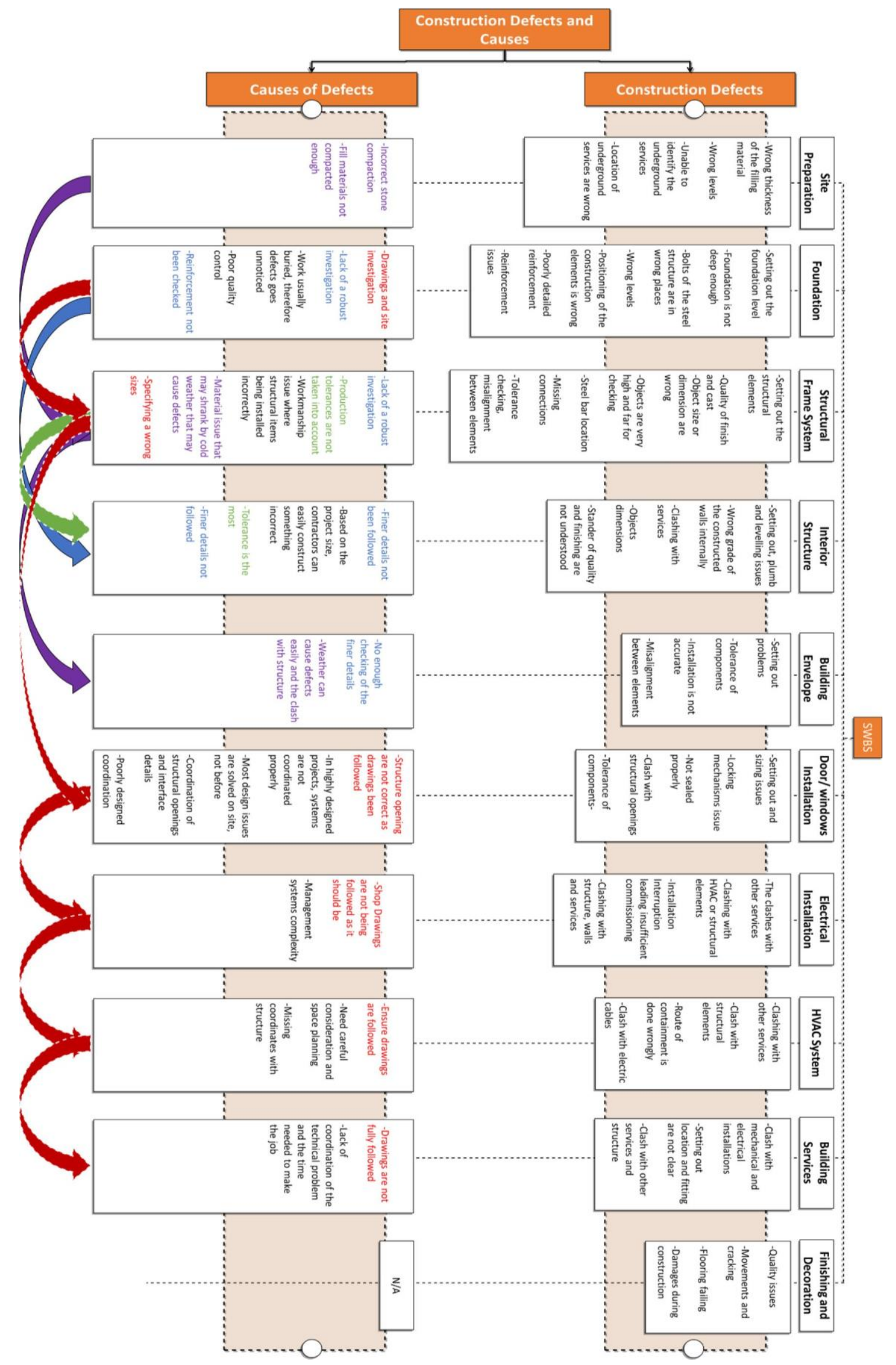

Figure 16. Common construction defects and causes in relation to construction stages. 


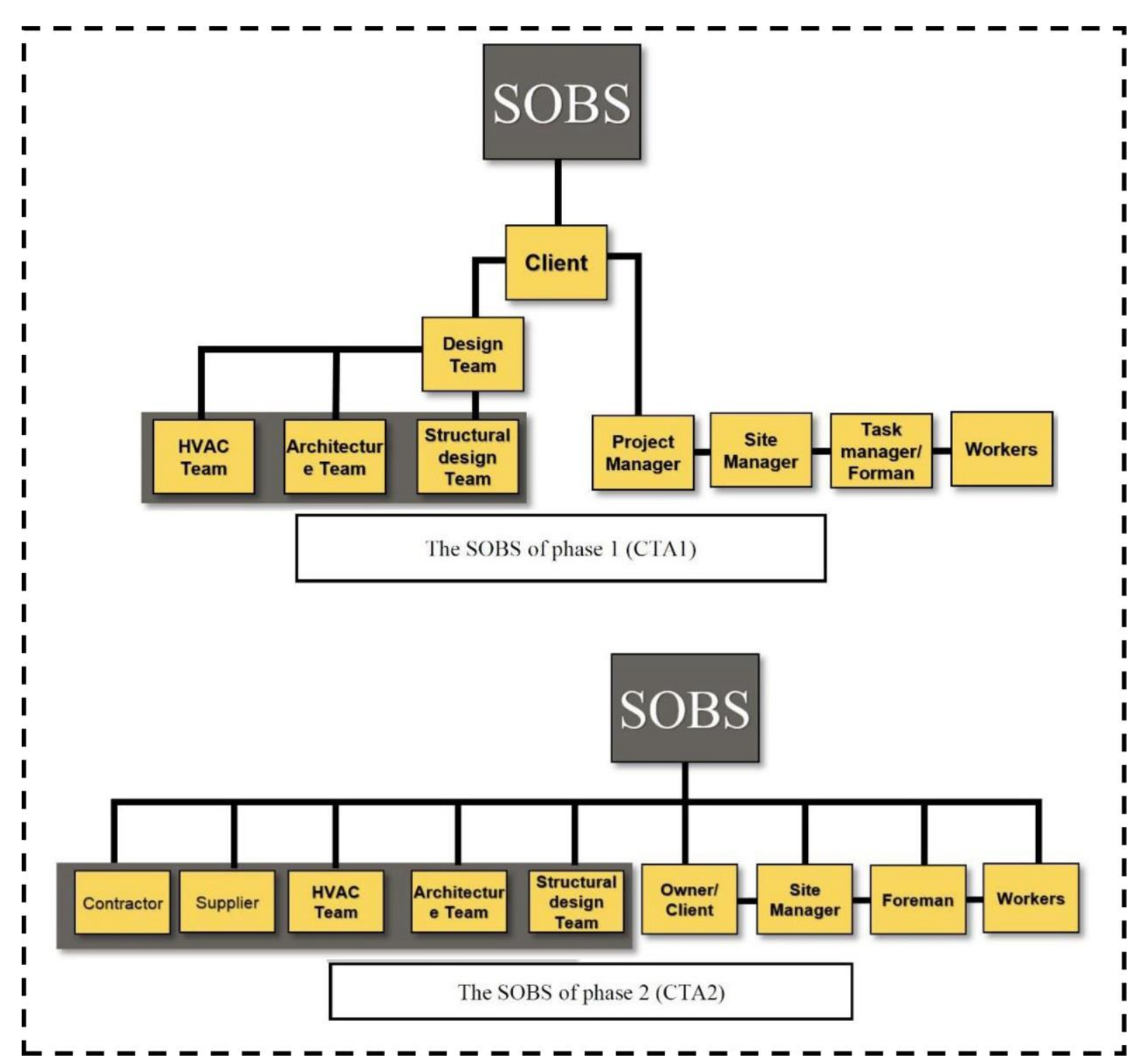

Figure 17. Team member structure comparison between CTA1 and CTA2.

\section{Step 5: Communication framework validation}

This step aims to validate the CTA 2 by testing one of the communication scenarios which will be achieved by counducting three meeting with G. F. Tomlinson Group. Meeting 1 is to define the construction stage where the study should be conducted and to defi- nine the study area. Metting 2 is hlep to identify the construction defects based on G.F. Tomlinson Group regulations. Next, the study willl register the construction site of the selected area in the form of a point cloud using the $3 \mathrm{D}$ laser scanning system. The next step is to create a 3D model from the point cloud data. The final step is to compare the 3D model of the 3D scan system with the 3D model of the BIM model. This comparison study will identify some defects that will be investigated in Meeting 3 through in interviews with the architects. They will describe the types of communication tool they used and compare these to what is found in the CTA 2.

\section{Results}

\section{SWBS and SOBS}

The SWBS illustrated in Figure 7 consists of the common tasks and stages found in the UK construction industry. It includes the Site Preparations, Foundations, Structure, Building Envelope, Interior Construction, Doors/Windows Installation, Electrical, Installation, HVAC system, Building Services Installation and Finishing and Decoration. For the SOBS, seven main working groups were identified: Worker, Foreman, Site Manager, Project Manager, Structural Engineer, Architect, and HVAC Engineer, as shown in Figure 8.

When all steps are achieved (WBS, OBS and communication tools), we can move on to assign the communication tools of phase 1 and phase 2 . The phase 1 result is denoted as Communication tool assignment 1 (CTA1) and the phase 2 result is denoted as Communication tool assignment 2 (CTA2).

\section{Communication framework of phase 1, CTA1}

As discussed above, the existing RAM does not include any specifications of communication tools and the causes of defects. Thus, we have developed a revised RAM that we name the CTA to fill this gap. The documentary analysis helped to identify the associated communication tools used by stakeholders in different construction stages. Moreover, the on-site observation helped to identify some of the missing communication tools. SWBS and 


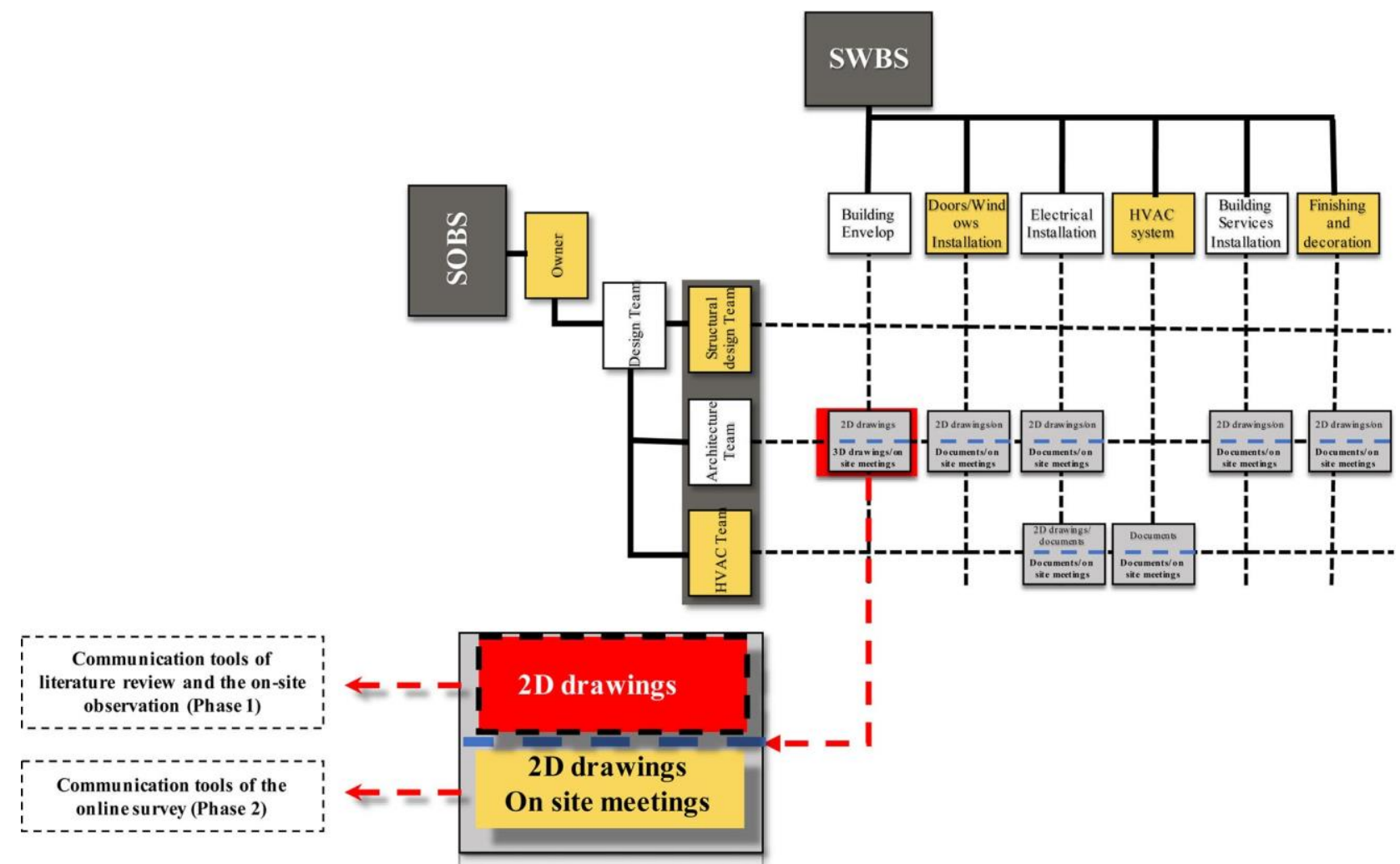

Figure 18. An example to illustrate the communication framework merging the literature review, site observation and survey data.

SOBS are set in a matrix table to form the CTA, as shown in Figure 9.

However, CTA1 is not free from error, and many researchers highlighted the issues they encountered. Some say, despite the fact that the hierarchical SOBS structure has the advantage of support- ing decision making, that on-site communication might be prone to errors, which can affect the problem-solving ability (Anderson and Brown 2010). In other words, it will isolate some organisations from the construction site communication as hierarchical SOBS assumes that some organisations will act on behalf of others, as seen in Figure 2. An example of that could be the architect consult- ant who acts on behalf of the owners, which means that owners are not fully integrated into the on-site communication (Hughes and Murdoch 2001). In reality, this is not always the case since each organisation has its own individual responsibilities. As a result of the complex hierarchical system, construction processes may be delayed, which will affect the overall cost, and cause further delays as consultants require the owner's confirmation for the most critical situations. Horizontal or flat SOBS as seen in Figure 3, on the other hand, forms equitable responsibilities where all organisational groups are equally involved in the construction site. In addition, the horizontal structure is a useful method if a company is looking to reduce costs by enhancing communication since it speeds up the decision making.

\section{Communication framework of phase 2, CTA2}

\section{Sampling characteristics}

The survey was structured into three sections. Section 1 includes the participants' personal and professional information. Section 2 investigates the stakeholders' responsibilities, while Section 3 seeks the participants' opinions of the possible defects resulting from poor communication. The survey was distributed among 328 participants who are construction professionals and academics in the UK, and we had 48 responses. The participants' list was obtained from the G.F. Tomlinson Group Ltd and the Linkedin websites, based on the job title and work experience. As seen in Figure 10 the majority of the respondents, around 47\%, have a Bachelor's degree, $13 \%$ possess a post-graduate qualification, and $6 \%$ have a vocational college degree while around $33 \%$ possess other types of qualification. The vast majority $(88 \%)$ of the respondents have at least five years' work experience (Figure 11), which ensures the reliability of the survey answers.

\section{Organisations involved in the construction}

The participants were asked to identify organisations that spend more time on-site. The results showed that all participants think the selected organisations are involved on-site while suppliers and site managers record $20 \%$ and $78 \%$, respectively (Figure 12). Indeed, it is clear that all organisations have a communication role on-site and no organisation is acting on behalf of another as specified in the hierarchical structure, Section 4.2. Site managers are expected to spend the most time on-site, as they have to con- trol and organise all construction activities. In addition, they have an ability to work on multiple tasks with several organisa- tions at the same time. On the other hand, contractors achieved almost $70 \%$ as they are the organisation responsible for carrying out the construction work and collaborating with others. In add- ition, the quoted results confirmed that a hierarchical SOBS, used in phase 1, is not convenient for this research as it does not provide sufficient information and is prone to error. This is clearly shown by the participants' recommendations as they sug- gested the involvement of all personnel to share equal communi- cation responsibilities on-site at the same level. Therefore, a new SOBS is developed to include Owners, Architect, Contractor, 


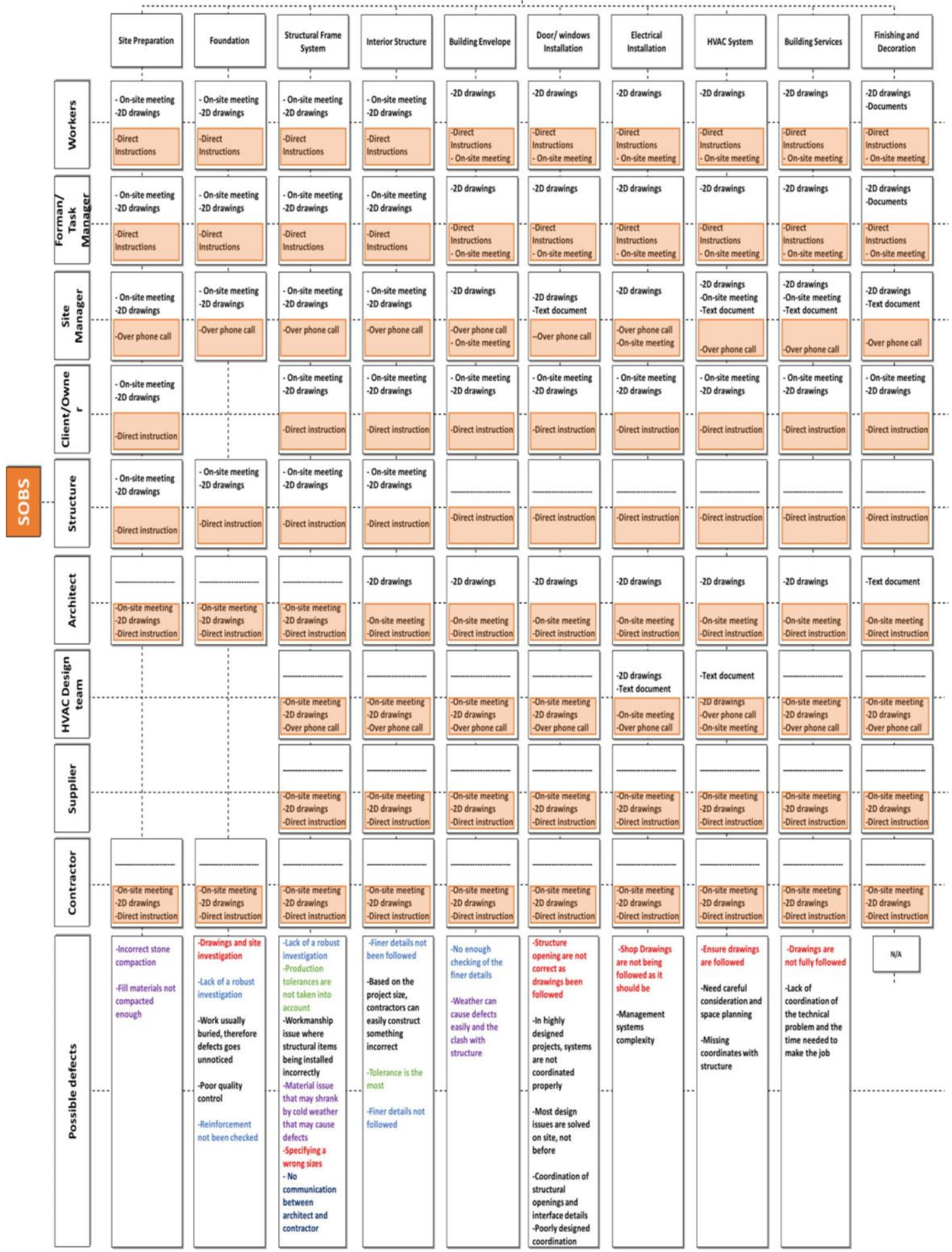

Figure 19. CTA2 illustrates the communication medium used by each team member in each construction stage.

Suppliers, Structural engineer, HVAC engineer, Site manager, Task manager/Foreman, and Worker.

\section{Ability to detect construction defects}

This section answers two questions in relation to organisations' responsibilities for detecting construction defects. The first question is about the organisation primarily responsible for detecting defects (Figure 13). The second question investigates which is the most efficient organisation for detecting defects (Figure 14). By using the two charts in Figures 12 and 13, the study revealed that participants think that site managers and contractors are the most important actors because of their involvement in the over- all construction stages that could justify their ability to detect defects. Figure 12 shows that participants consider that site man- agers, with a score of $88 \%$, are the most responsible for detecting 


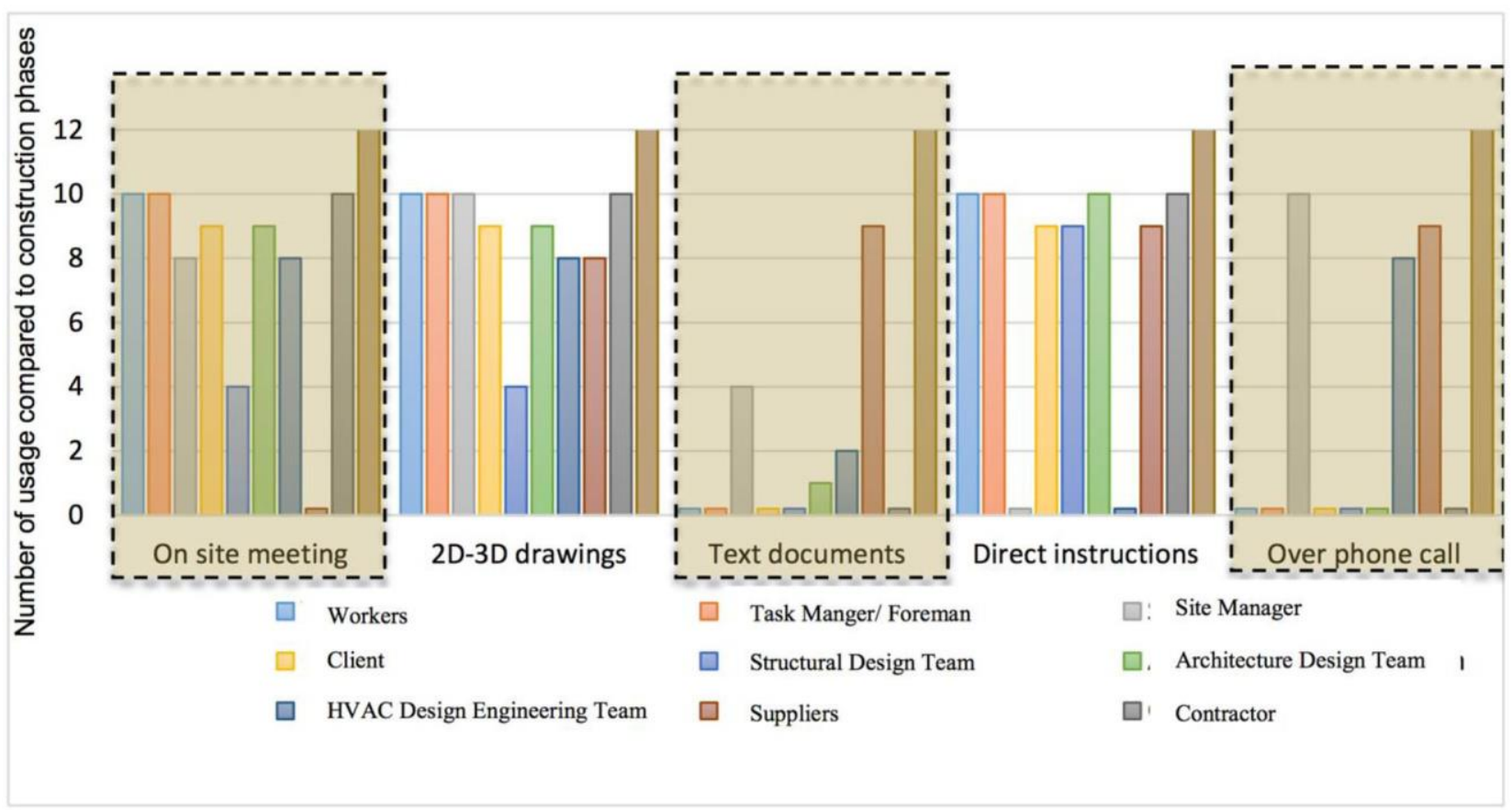

Figure 20. Communication methods used to support on-site construction.

defects on the construction site. Contractors came in second place with $70 \%$, followed by the architectural team and task manager/ foreman with $64 \%$. The data from the second question give a differ- ent answer compared to question one (Figure 13). Participants think that site managers are the best team for detecting defects while contractors and task managers were ranked second. Therefore, contractors and task managers need to collaborate more efficiently. In addition, Figures 13 and 14 show that suppliers are responsible for detecting defects, but only by $20 \%$. For example, suppliers do not clearly understand the $2 \mathrm{D}$ and deliver the wrong materials to the construction site, which can cause construction defects or a work delay in order to redeliver the correct materials.

Construction stages exposed to construction defects and causes

Based on the survey findings (Figure 15), Interior Construction, Building Envelope and Finishing are the construction stages most exposed to defects at $75.9 \%, 74.4 \%$ and $69.3 \%$, respectively. In addition, construction defect in the building envelope could lead to damage to other internal building components since it acts as the first layer of protection against external climatic conditions such as rain, humidity and other weather conditions (Fallis 2013). For instance, water infiltration into the building's interior through the building envelope can affect the structure significantly. Apart from the defects caused by external climatic conditions, unplanned changes in structural elements such as the re-dimensioning of col- umns without the structural design team's approval usually cause delays and some construction defects (Fallis 2013).

Another question relates to the common types of defect found and their causes at each construction stage. The study revealed a range of defects related to material specifications, partitions and services located at the stage of site preparation. All types of construction defect are summarised in Figure 16, showing each construction stage and the related defects. Furthermore, the finding summarises the causes in four main categories - material, drawings, inspection and tolerance issues. These results are implemented later in the CTA2 framework in order to inform organisations of the potential defects that they need to be aware of.

\section{Organisation breakdown structure optimisation}

The study has implemented two recommendations suggested by experts. First, unlike the CTA1, where the owner is isolated from the communication on-site, the CTA2 follows the experts' recommendations that the owner should be involved in the construction stages as discussed in Section 4.2. The second recommendation is to include contractors and suppliers in the communication framework (Figure 17).

\section{Combination of data}

Figure 18 illustrates a developed communication framework which combines data from phase 1 (literature review and site observation) and phase 2 (the online survey). These matrix cells are divided horizontally into two sections. The upper section shows the communication tools found in phase 1 , whereas the lower section shows tools found in phase 2.

\section{Communication framework of phase 2, CTA2}

The final framework is named CAT2 and is used to identify the appropriate communication tools for each organisation at each construction stage. The CTA 2 uses the survey data to enrich and confirm the information of the CTA1. In addition, the following section titled 'Causes of Defects' is added to inform organisations of the potential construction defects (Figure 19). The CTA2 will facilitate the construction site communication and the implementation of BIM Level 3 during the construction stage.

\section{CTA2: Communication tool assignment matrix findings}

The CTA2 adds two additional communication tools compared to the three found in the CTA1. In addition to the $2 \mathrm{D}$ and $3 \mathrm{D}$ 

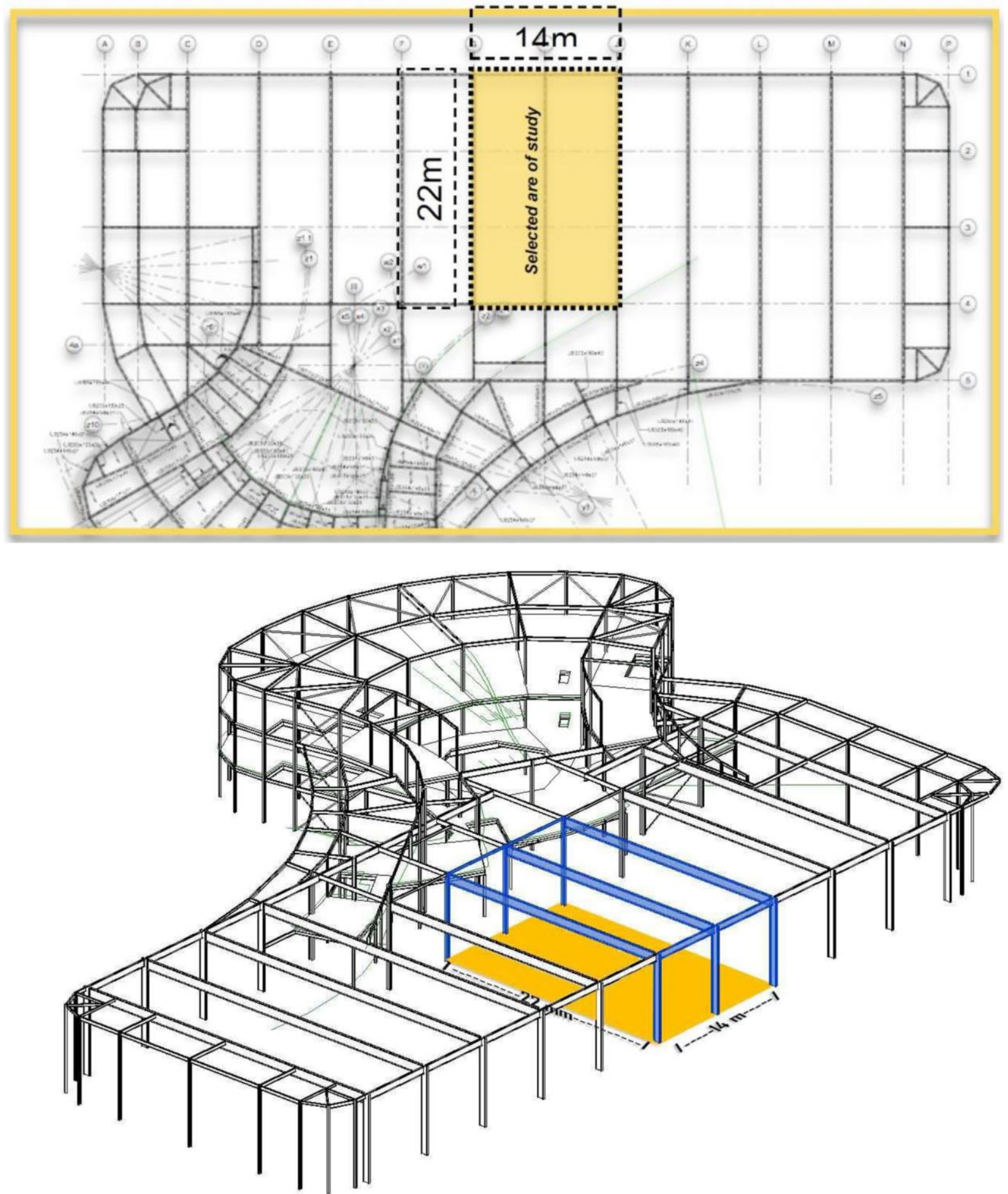

Figure 21. The selected area of the study defined by the G.F. Tomlinson group.

drawings, on-site meetings and document-based communication, the survey adds tools that give direct instructions and phone calls, as these are recommended by the experts to solve compli- cated communication issues. Based on the number of tools used throughout the construction stages, 2D and 3D drawings score the highest rate of usage. On-site meetings come in second place while using text documents appears to be the least effective tool and its usage is limited to suppliers and site managers at a spe- cific stage, such as finishing and decoration (Figure 20).

These findings will be tested and evaluated in the following section by applying a field test using the 3D scanning system.
That will help define construction defects and then investigate their causes by conducting an interview with the architects from the $\mathrm{G}$. F. Tomlinson group.

\section{Validation study}

The validation process involves three meetings with the G. F. Tomlinson group to serve different objectives. Meeting 1 is to help define the construction stage where the study needs to be conducted as well as the study area. Meeting 2 is to discuss the 
criteria that define the construction defects. Meeting 3 is an interview to present results, investigate causes of defects, and identify the communication tools used. Once the data from the interviews are assessed, the study will compare the resulting communication tool used with tools found in the CTA2 frame- work. Each meeting is discussed in the following section.

Meeting 1: It was found previously that the interior construc- tion stage (structural frame/column, beams) is the one most exposed to construction defects, see Figure 15. In addition, the

G.F. Tomlinson group advised that we conduct the validation study on this stage and compare the communication tools related to the architect group with the tools found in the CTA2. As for the study area, the G.F. Tomlinson group advised us to select the

central area of $14 \mathrm{~m}^{*} 22 \mathrm{~m}$ of the project as highlighted in yellow in Figure 21.

Meeting 2: on the other hand, defind two criteria related to columns and beams dimensions and location coordinates to identify the construction defect in the steel structure.

- Columns and beams dimensions is $\mathrm{p} /-10 \mathrm{~mm}$.

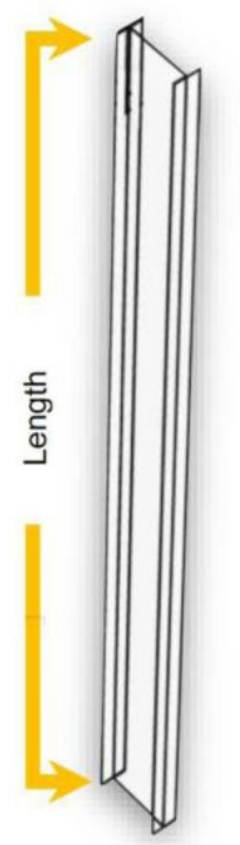

Columns Height +/- 10mm

Figure 22. Columns and beam dimensions.
- Columns and beams positioning/location coordinates i\$p/$3 \mathrm{~mm}$, see Figure 22.

The next step is to collect the data of the construction site as point cloud data usng the Leica P20 system for 3D scanning sys- tem, see Figure 23. That is followed with data processing and cleaning leading to the creation of a BIM model for the constuc- tion site as seen in Figures 24 and 25.

\section{Validation study results}

The study area containe three columuns and three beams as seen in the BIM model of the design stage. Based on meeting 2 outcomes, the validation study is focused on two aspcets of dimensions and location coordinates. The study found dimensions and location issues that are more than the accepted tolerance of $\mathrm{p} /-$ $10 \mathrm{~mm}$ and $\mathrm{p} /-3 \mathrm{~mm}$, respectively. In addition, we found another two types of defect related to structure specifications and number of the structural objects which is disscused in the following section.

\section{Dimensions defects}

The study shows that all beams and colmuns found in the BIM model of the design stage have some diffrences to the BIM model of the 3D scanning model. In fact, some of these dimen- sions are more than the accepted tolerance of / $10 \mathrm{~mm}$ iderptified in meeting 2: See Table 1 and Figure 26.

\section{Structure spacifications}

It was found that beams in the BIM model of the design stage are spacified differently to the one found in the 3D scanned model. The BIM model of the 3D scan model stage is specified with a cellular beam type whereas the BIM of the design model has a plain type of beam, see Figure 27.

\section{Number of columns}

As for the number of the structural columns, the study shows some differences that are worth highlighted. It was found that the BIM model of the design stage in the study area has three beams and six columns with two columns on each side of each beam as seen in Figure 21. The 3D scan model, on the other hand, shows that there is a missing column in the middle, mak- ing the structure consist of three beams and only five columns, see Figure 28 .

Meeting 3: This meeting was conducted to present the three results found to Chris Hedley, the Design Manager, and Mark Armitage, who is the Assistant Design and Building Coordinator,
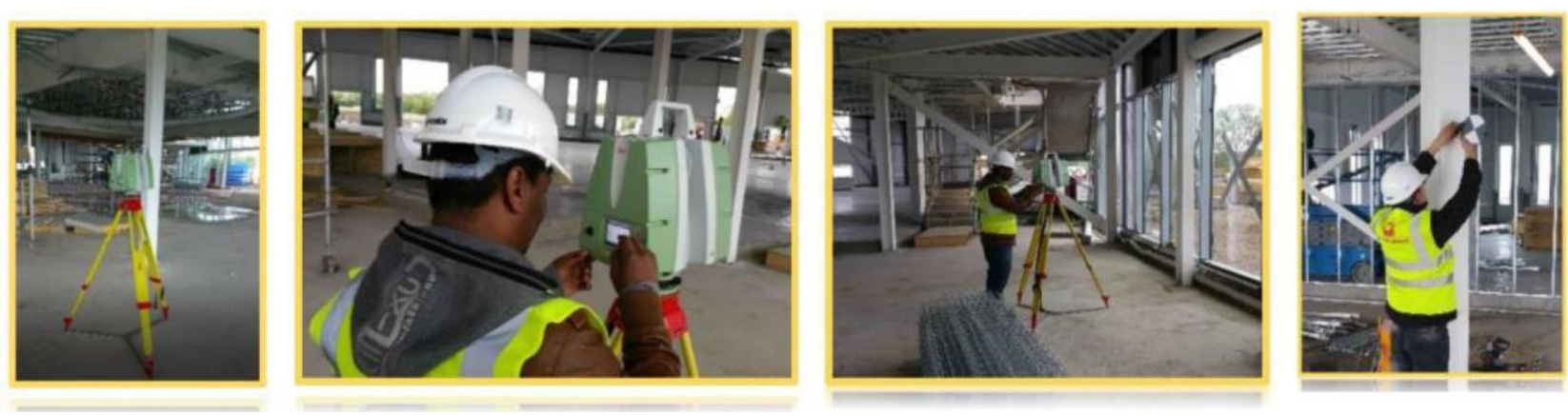

Figure 23. The scanning process. 


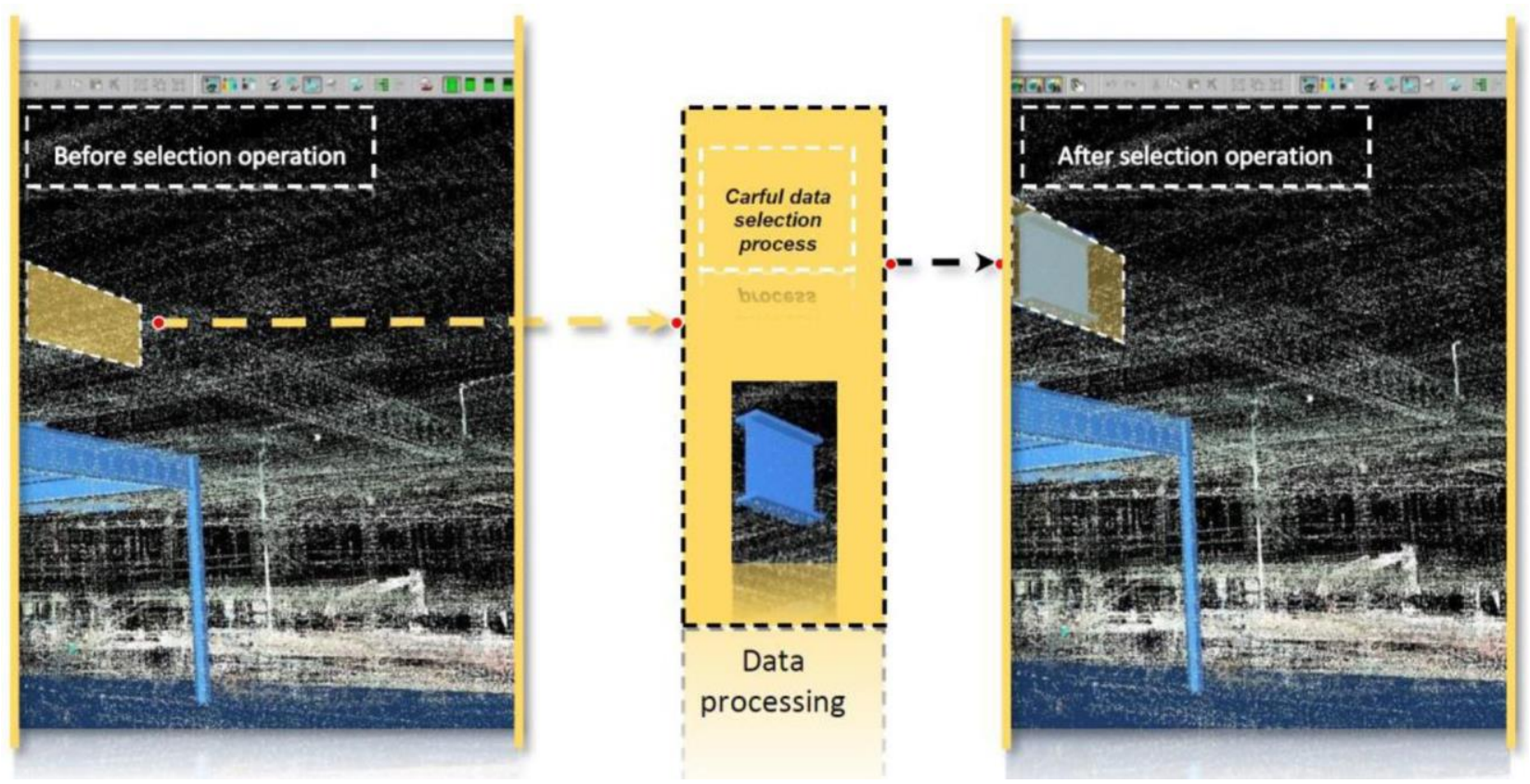

Figure 24. Process of building the 3D solid using Cyclone 9.1.
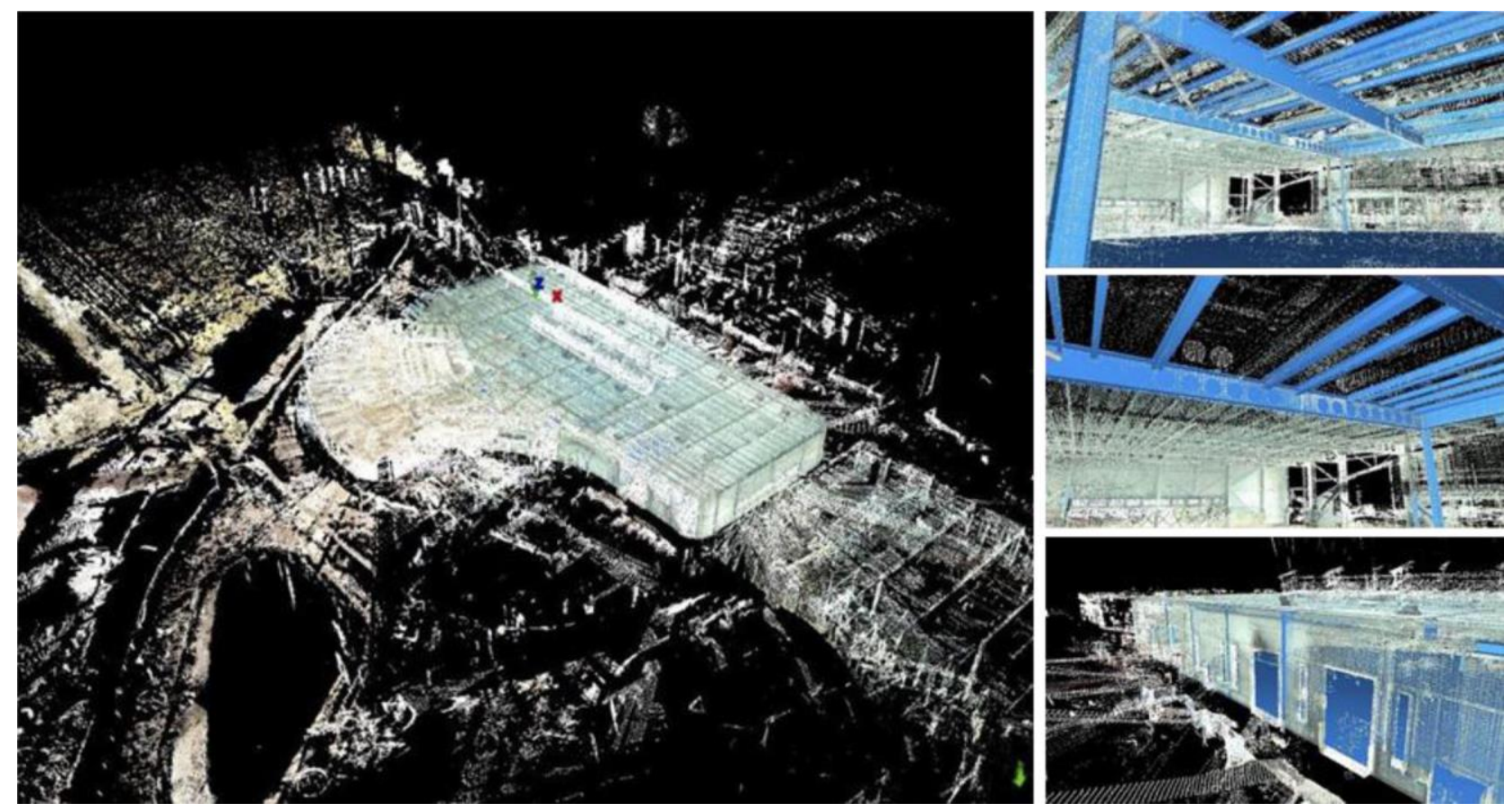

Figure 25. The full point cloud data of the 3D scan.

Table 1. Showing the defenses in measurement of beams and columns.

\begin{tabular}{lllc}
\hline & 3 C Scan model & BIN model & Tota differences \\
\hline Beam's Width & $21.80 \mathrm{~m}$ & $22.01 \mathrm{~m}$ & $0.21 \mathrm{~m}$ \\
Beam's Height & $0.941 \mathrm{~m}$ & $0.93 \mathrm{~m}$ & $0.11 \mathrm{~m}$ \\
Beam's Thickness & $0.289 \mathrm{~m}$ & $0.29 \mathrm{~m}$ & $0.2 \mathrm{~m}$ \\
& & & \\
Column's Width & $0.623 \mathrm{~m}$ & $0.60 \mathrm{~m}$ & $0.21 \mathrm{~m}$ \\
Column's Height & $0.6981 \mathrm{~m}$ & $7.02 \mathrm{~m}$ & $0.39 \mathrm{~m}$ \\
Column's Thickness & $0.227 \mathrm{~m}$ & $0.228 \mathrm{~m}$ & $1 \mathrm{~mm}$ \\
& & & \\
Distances between beams and columns & $7.26 \mathrm{~m}$ & $7.227 \mathrm{~m}$ & $0.42 \mathrm{~m}$ \\
\hline
\end{tabular}




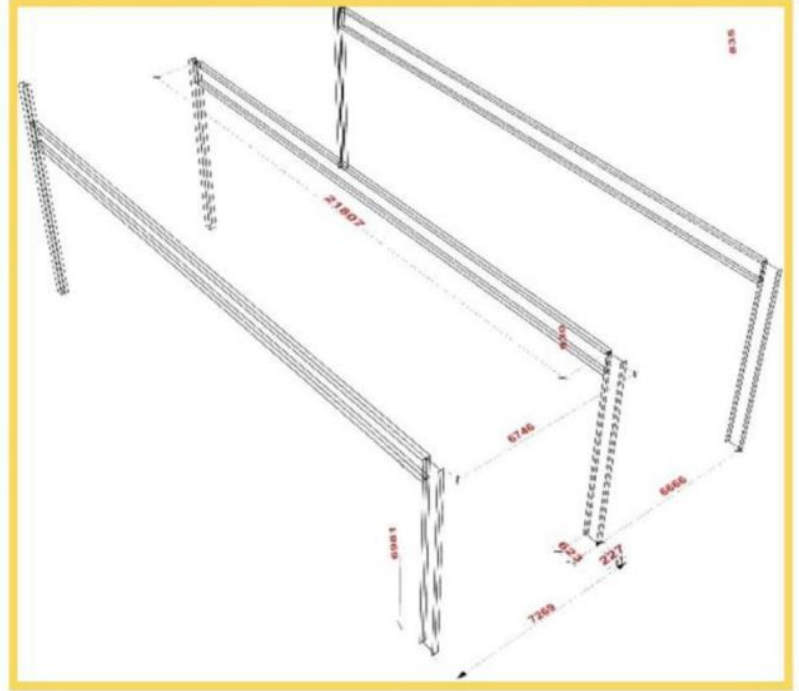

The 3D scan model

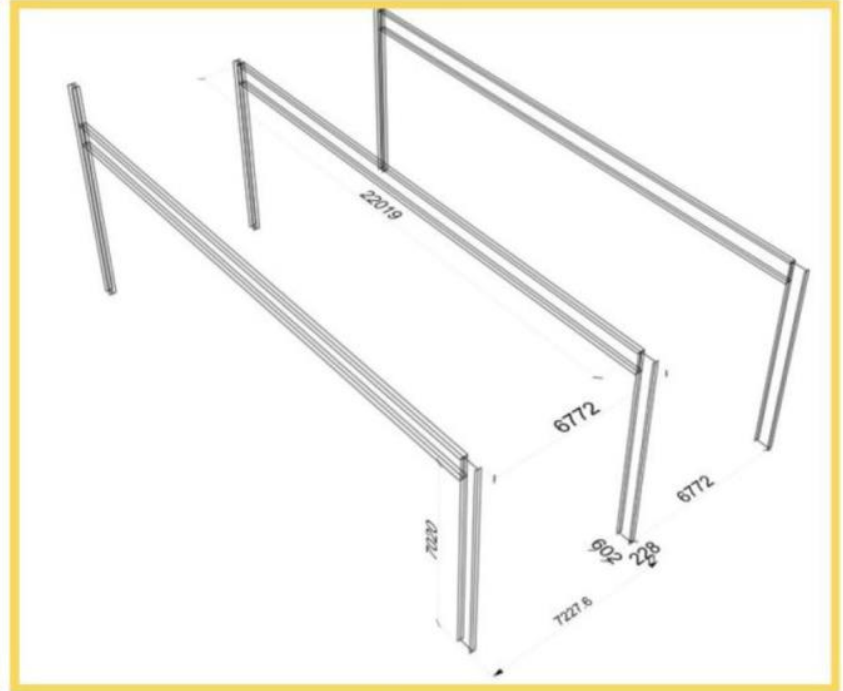

$\mathrm{BIM} / \mathrm{IFC}$ file

Figure 26. Showing the dimension differences between the scanned model and designed model.

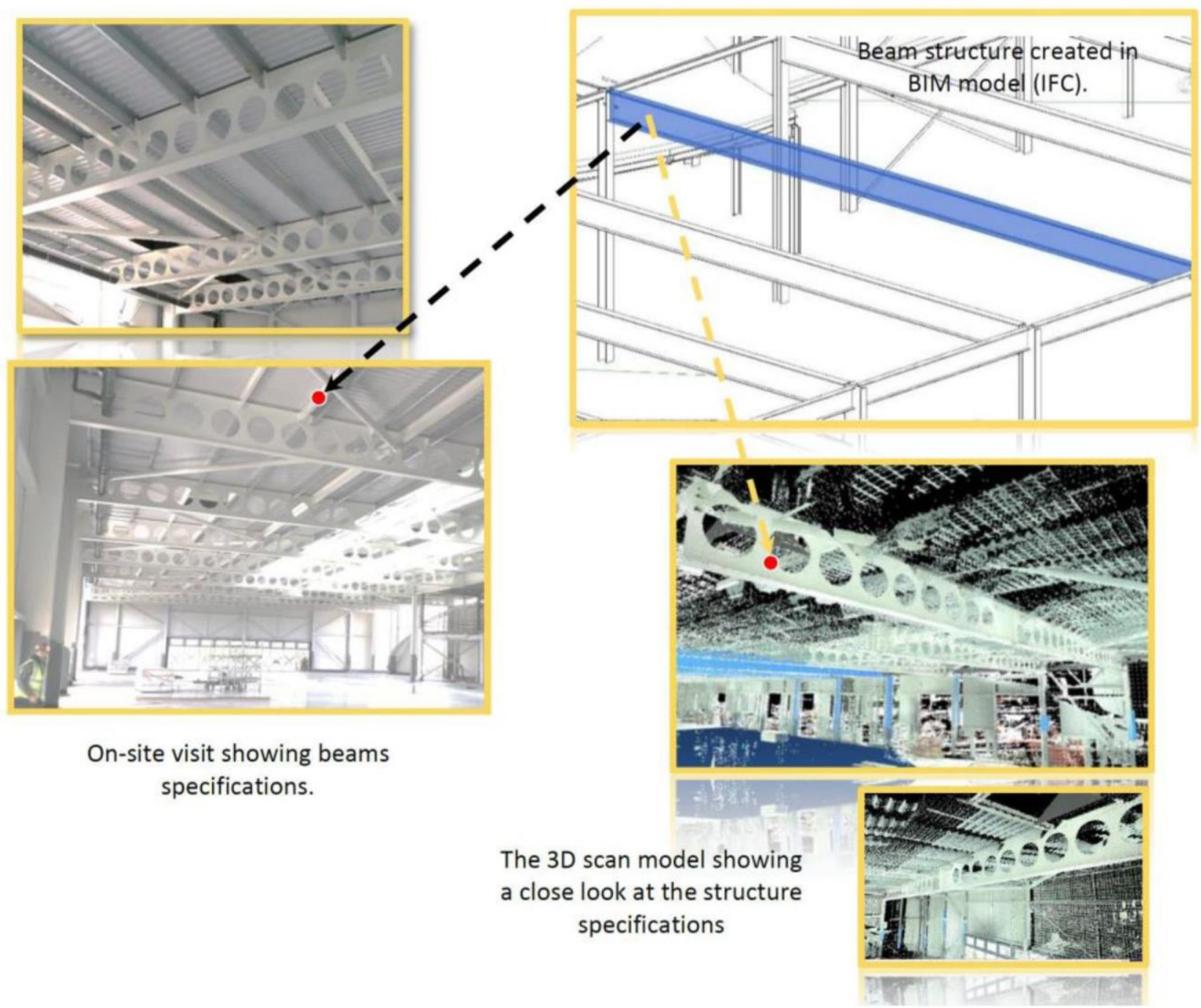

Figure 27. Showing the specification differences between designed model and 3D scan and confirmed with the site visit. 


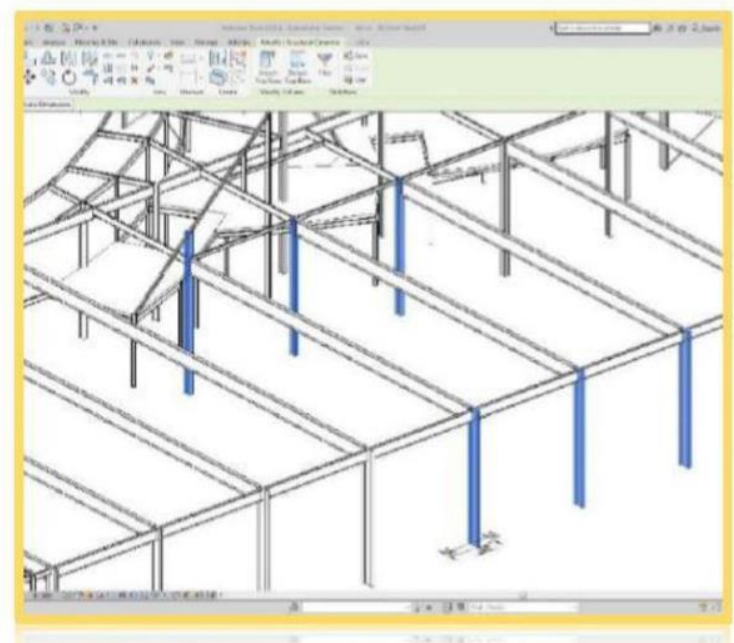

The six columns made in the IFC file highlighted in blue colour.

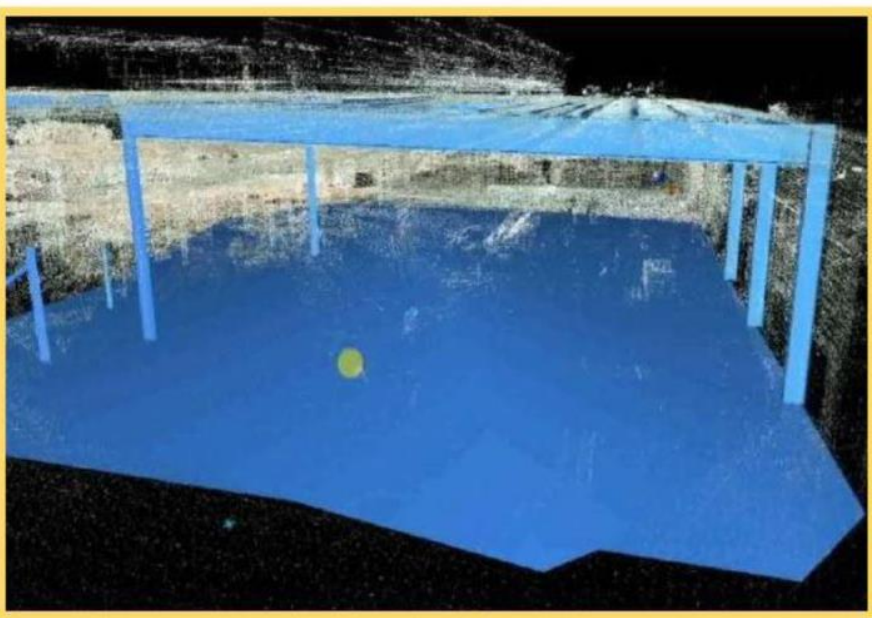

The only five columns found in the 3D laser scan, three on one side and two on the other side.

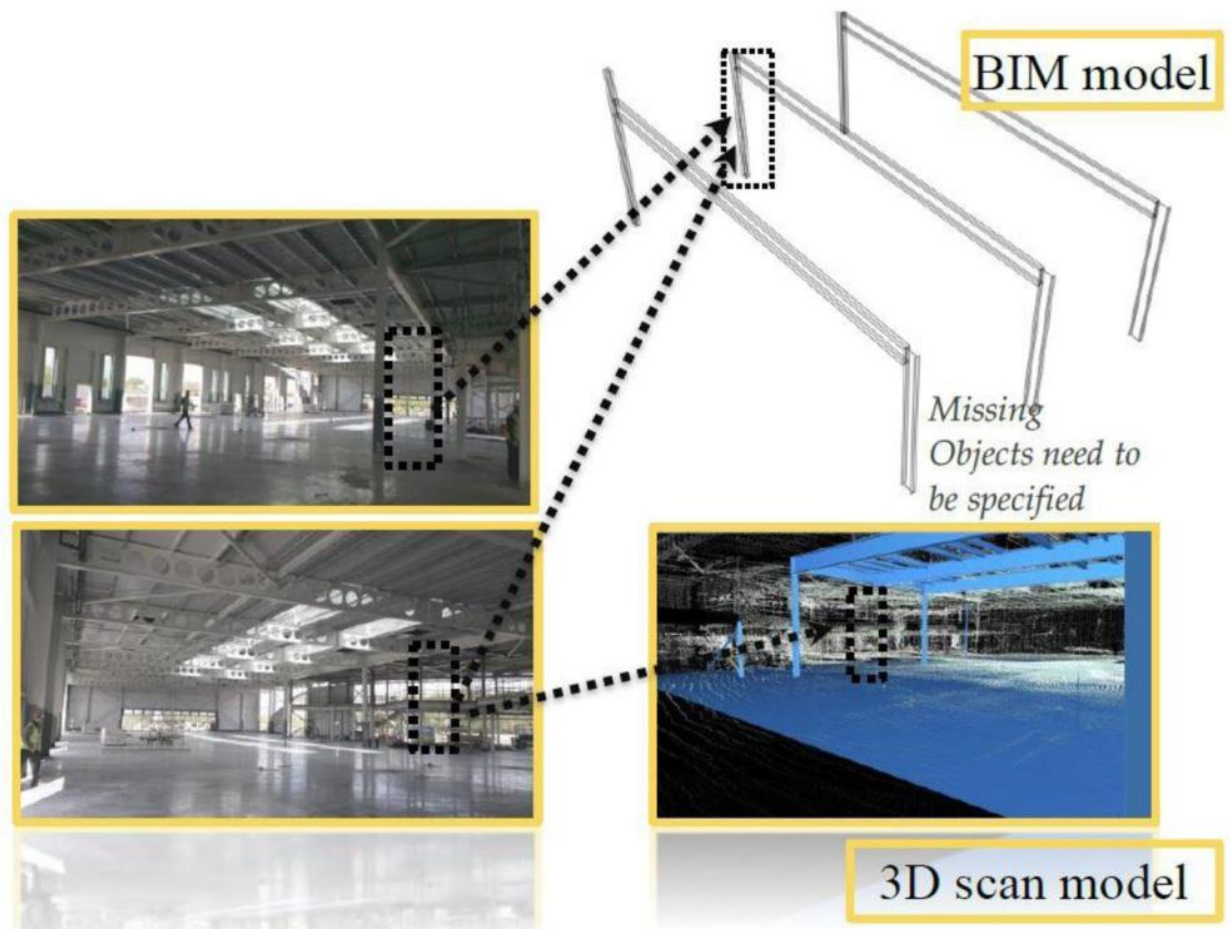

Figure 28. Number of the structural columns in the 3D scan model and the BIM file.

both from the G.F. Tomlinson group. In addition, this meeting has one main question to answer:

- What types of communication tools have you used as a design manager and design assistant to communicate with the fabrication company that led to these defects?

Their response was that, once the steel structure design documents are approved, this passes directly to the steel fabrication company which is another organisation that works off-site. After this point, neither the design manager nor the architects nor the structural design team follows up on how the design is being translated to a working structure. Instead, architects and the structural design team's job was transformed into an advisory role in the case that the fabrication company seeks advice. Another point mentioned was that the communication tools used between the G.F. Tomlinson group and the fabrication company were made by the by web-based system (Lima) or by sending documents via e-mail in this case.

\section{Conclusion}

The study was carried out to answer three questions. First, what are the most effective communication tools used on construction sites? Second, which team members are best qualified to be sup- ported with BIM? Third, which construction stages are more exposed to defects? Answering these questions has led to devel- oping a communication framework, CTA2, describing the 
recommended communication activity at each construction stage for each organisation.

Addressing the first question investigating the communication tools used in practice, the study found that 2D and 3D shop drawings tended to be the most popular. Indeed, they remain the most preferred tool due to their frequent usage by stakeholders/ organisations throughout the 10 construction stages selected for this study. However, 2D and 3D drawings have limited effective- ness, as only experts are able to use them for communication, which is supported by Wang (2007). Concerning the second question of knowing the most effective organisation on-site, site managers and contractors both show an effective ability in deal- ing with the 2D/3D drawings, conducting an on-site meeting and text document, particularly if they need to discuss the work- ing tasks with other stakeholders who are not present on-site, such as suppliers. Moreover, site managers can also organise fre- quent onsite meetings when necessary. The findings suggest supporting two organisations - the site managers and contractors

- with a BIM tool, unlike other research, which selected only one stakeholder. Finally, as relates to the third question, it appears that interior construction is the stage most exposed to construction defects.

The validation aspect results show that no two-way communication took place between the architects and the supplier (the fabrication company) in this study. Instead, their job was only to pass on documents using the online service and e-mails; none of the tools found in the CTA 2 framework was used for this pro- cess. Therefore, we assume that no types of communication tool are used apart from the online service and e-mail.

\section{Future work}

We plan to conduct further research starting with the types of data that need to be communicated and how these will affect the communication framework and to carry out an examination of the communication framework in Figure 18. One communica- tion cell scenario will be selected (the intersection cell of archi- tecture organisation and structure stage for example) for further investigation. Next, we will select a construction site as a case study and use a 3D laser scan to create a BIM model from the point cloud. Then we will compare the created BIM file with the one used at the design stage. The comparison results will be pre- sented to the architects for a contextual analysis to explain the findings.

\section{Acknowledgements}

We would like to thank Al-Baha University (Kingdom of Saudi Arabia) for sponsoring this work which is a part of a $\mathrm{PhD}$ research conducted in 2019. In addition, we thank the G. F. Tomlinson Group Ltd who supported us to find eligible participants for the sur- vey. The results obtained were crucial and relevant to the study. The time the participants took to complete the survey is appreciated.

\section{Disclosure statement}

No potential conflict of interest was reported by the author(s).

\section{References}

Ahankoob A, Manley K, Abbasnejad B. 2019. The role of contractors' building information modelling (BIM) experience in realising the potential values of BIM. Int J Constr Manage. 1-12. doi: 10.1080/15623599.2019. 1639126.

Alreshidi E, Mourshed M, Rezgui Y. 2016a. Cloud-based bim governance platform requirements and specifications: software engineering approach using BPMN and UML. J Comput Civ Eng. 30(4):4015063. doi: 10.1061/ (ASCE)CP.1943-5487.0000539.

Alreshidi E, Mourshed M, Rezgui Y. 2016b. Requirements for cloud-based BIM governance solutions to facilitate team collaboration in construction projects. Requirements Eng. 23(1):1-31. doi: 10.1007/s00766-016-0254-6.

Alwisy A, Bu Hamdan S, Barkokebas B, Bouferguene A, Al-Hussein M. 2019 A BIM-based automation of design and drafting for manufacturing of wood panels for modular residential buildings. Int J Constr Manage. 19(3):187-205. doi: 10.1080/15623599.2017.1411458.

Anderson C, Brown CE. 2010. The functions and dysfunctions of hierarchy. Res Organizational Behav. 30(C):55-89. doi: 10.1016/j.riob.2010.08.002.

Atkinson AR. 1999. The role of human error in construction defects. Struct Surv. 17(4):231-236. doi: 10.1108/02630809910303006.

Bridges L. 2016. Government construction strategy 2016-20.

BSI. 2014. PAS 1192-3:2014 Specification for information management for the operational phase of assets using building information modelling. BSI Stand Publ. 1(3):1-44

Cabinet Office. 2011. Government construction strategy. Construction. 96(5): 43.

Chudley R, Greeno R. 2008. Data for architects desingning and construction engineers and contractors. In: Building construction handbook. Abingdon (OX): Routledge.

Dainty A, Moore D. 2006. Communication in construction teams. Abingdon (OX): Routledge.

Emmitt S, Gorse C. 2011. A "missing" family of classical orthogonal polynomials. J Physics A: Math Theor. 44(8):85201.

Fallis A. 2013. Summary for policymakers. In: Climate change 2013 - The physical science basis. Cambridge: Cambridge University Press; p. 1-30.

Goh KC, et al. 2014. Enhancing communication in construction industry through BIM. 11th International Conference on Innovation and Management. [accessed 2018 Jan 7]. http://eprints.uthm.edu.my/6696/.

Golany B, Shtub A. 2001. Work breakdown structure 2. In: Handbook of industrial engineering. Hoboken, NJ, USA: Wiley; p. 1263-1280.

$\mathrm{Gu}$ N, London K. 2010. Understanding and facilitating BIM adoption in the AEC industry. Autom Constr. 19(8):988-999. doi: 10.1016/j.autcon.2010. 09.002.

Hollermann S, Melzner J, Bargstadt HJ. 2012. BIM - A challenge for communication between parties involved in construction. eWork and eBusiness in Architecture, Engineering and Construction - Proceedings of the European Conference on Product and Process Modelling 2012, ECPPM 2012; October 2016. p. 833-838.

Howard R, Penttila H. 2006. Describing the changes in architectural informa- tion free-form architectural expression. ITcon. 11(1):395-408. http:// itcon.org/2006/29/.

Hughes W, Murdoch J. 2001. Roles in construction projects: Analysis \& terminology. Birmingham: Construction Industry Publications.

Josephson P, Hammarlund Y. 1999. Causes of defects in construction a study of seven building projects in Sweden. Autom Constr. 8(6):681-687. doi: 10.1016/S0926-5805(98)00114-9.

Khosrowshahi F, Arayici Y. 2012. Roadmap for implementation of BIM in the UK construction industry. Eng Const Arch Man. 19(6):610-635. doi: $10.1108 / 09699981211277531$.

Len I, Garca J. 2011. The influence of organizational structure on organizational learning. Int J Manpower. 32(5/6):537-566.

Love PED, Li H. 2000. Quantifying the causes and costs of rework in construction. Constr Manage Econ. 18(4):479-490. doi: 10.1080/ 01446190050024897.

MacLeamy P. 2016. Industrial strategy: Government and industry in partnership. Construction. 2025(7):78.

Melnic A, Puiu T. 2011. The management of human resources within proj- ects: The structures of the project team, the responsibility assignment matrix. Economy Transdisciplinary Cognition. 14(1):476-484.

Melnic A-S, Puiu T. 2011. The management of human resources within proj-ects: the structures of the project team, the responsibility assignment matrix. Bacau. http://search.proquest.com/docview/1118585011/.

Mills A, Love PE, Williams P. 2009. Defect costs in residential construction. J Constr Eng Manage. 135(1):12-16. doi: 10.1061/(ASCE)07339364(2009)135:1(12).

Modi SB, Mabert VA. 2007. Supplier development: Improving supplier performance through knowledge transfer. J Oper Manage. 25(1):42-64. doi: 10.1016/j.jom.2006.02.001.

Mulenburg G. 2010. Work breakdown structures: The foundation for project management excellence by Eric S.Norman, Shelly A. Brotherton, and 
Robert T. Fried. J Prod Innovation Manage. 27(5):779-781. doi: 10.1111/j. 1540-5885.2010.00750_1.x.

Oh M, Lee J, Hong SW, Jeong Y. 2015a. Integrated system for BIM-based collaborative design. Autom Constr. 58:196-206. doi: 10.1016/j.autcon. 2015.07.015.

Oh M, Lee J, Hong SW, Jeong Y. 2015b. Integrated system for BIM-based collaborative design. Autom Constr. 58:196-206. doi: 10.1016/j.autcon. 2015.07.015.

Park C-S, Lee D-Y, Kwon O-S, Wang X. 2013. A framework for proactive construction defect management using BIM, augmented reality and ontology-based data collection template. Autom Constr. 33:61-71. doi: 10.1016/ j.autcon.2012.09.010.

Rev E. 2003. Work breakdown structure. Project Manage Practices (Work Breakdown Struct). 7:1-3.

Rossi A. 2012. From drawing to technical drawing. Nexus Netw J. 14(1): 135149. doi: 10.1007/s00004-011-0102-4.

Rounce G. 1998. Quality, waste and cost considerations in architectural building design management. Int $\mathrm{J}$ Project Manage. 16(2):123-127. doi: 10.1016/S0263-7863(97)00042-2.

Senaratne S, Ruwanpura M. 2015. Communication in construction: a management perspective through case studies in Sri Lanka. Architect Eng Des Manage. 12(1):1-16.

Shirkavand I, Lohne J, Laedre O. 2016. Defects at handover in Norwegian construction projects. Procedia - Social Behav Sci. 226:3-11. doi: 10.1016/ j.sbspro.2016.06.155.
Shrahily RY, et al. 2015. Communication framework to support more effect- ive onsite construction monitoring. WIT Trans Built Environ. 149: 195-203.

Shrahily RY, et al. 2016. Construction site communication study using the RAM management system for BIM adaptation. Int J 3-D Inf Model. 5(4):39-53.

Srivastav AK. 2010. Impact of ISO 9000 implementation on the organisation. Int J Qual Reliability Mgmt. 27(4):438-450. doi: 10.1108/ 02656711011035138.

Steel J, Drogemuller R, Toth B. 2012. Model interoperability in building information modelling. Softw Syst Model. 11(1):99-109. doi: 10.1007/ s10270-010-0178-4.

Stupart A. 2003. Construction site. [accessed 2018 Jan 6]. https://www.brebookshop.com/details.jsp?id=140323.

Tjell J, Bosch-Sijtsema PM. 2015. Visual management in mid-sized construction design projects. Procedia Econ Finance. 21:193-200. doi: 10.1016/ S2212-5671(15)00167-7.

Wang X. 2007. Using augmented reality to plan virtual construction worksite. Int J Adv Rob Syst. 4(4):42. doi: 10.5772/5677.

Wu Q, Fan L. 2008. On an integrated RAM aware enterprise process control system. In 2008 4th International Conference on Wireless Communications, Networking and Mobile Computing. IEEE, p. 1-4.

Yang T, Chen CW. 2009. An incentive pay system for project management based on responsibility assignment matrix and fuzzy linguistic variables. Expert Syst Appl. 36(10):12585-12591. doi: 10.1016/j.eswa.2009.05.067.

Yu WD, Hsu JY. 2013. Content-based text mining technique for retrieval of CAD documents. Autom Constr. 31:65-74. doi: 10.1016/j.autcon.2012.11.037. 